This document is the Accepted Manuscript version of a Published Work that appeared in final form in ACS Applied Materials and Interfaces, copyright (c) American Chemical Society after peer review and technical editing by the publisher. To access the final edited and published work see: https://dx.doi.org/10.1021/acsami.8b15379. 


\section{Energy, Environmental, and Catalysis Applications}

\section{Tailoring Copper Foam with Silver Dendrite Catalysts for Highly Selective Carbon Dioxide Conversion into Carbon Monoxide}

Félix Urbain, PengYi Tang, Nina M. Carretero, Teresa Andreu, Jordi Arbiol, and Joan R Morante ACS Appl. Mater. Interfaces, Just Accepted Manuscript • DOI: 10.1021/acsami.8b15379 • Publication Date (Web): 27 Nov 2018 Downloaded from http://pubs.acs.org on November 30, 2018

\section{Just Accepted}

"Just Accepted" manuscripts have been peer-reviewed and accepted for publication. They are posted online prior to technical editing, formatting for publication and author proofing. The American Chemical Society provides "Just Accepted" as a service to the research community to expedite the dissemination of scientific material as soon as possible after acceptance. "Just Accepted" manuscripts appear in full in PDF format accompanied by an HTML abstract. "Just Accepted" manuscripts have been fully peer reviewed, but should not be considered the official version of record. They are citable by the Digital Object Identifier (DOI@). "Just Accepted" is an optional service offered to authors. Therefore, the "Just Accepted" Web site may not include all articles that will be published in the journal. After a manuscript is technically edited and formatted, it will be removed from the "Just Accepted" Web site and published as an ASAP article. Note that technical editing may introduce minor changes to the manuscript text and/or graphics which could affect content, and all legal disclaimers and ethical guidelines that apply to the journal pertain. ACS cannot be held responsible for errors or consequences arising from the use of information contained in these "Just Accepted" manuscripts. 


\title{
Tailoring Copper Foam with Silver Dendrite Catalysts for Highly Selective Carbon Dioxide Conversion into Carbon Monoxide
}

Félix Urbain $^{1 *}$, Pengyi Tang ${ }^{1,2}$, Nina M. Carretero ${ }^{1}$, Teresa Andreu ${ }^{1,3}$, Jordi Arbiol $^{2,4}$, and Joan Ramon Morante,

${ }^{1}$ IREC, Catalonia Institute for Energy Research, Jardins de les Dones de Negre 1, 08930 Sant

Adrià de Besòs, Barcelona, Catalonia, Spain

${ }^{2}$ Catalan Institute of Nanoscience and Nanotechnology (ICN2), CSIC and BIST, Campus UAB, Bellaterra, 08193 Barcelona, Catalonia, Spain

${ }^{3}$ Universitat Politècnica de Catalunya, Jordi Girona 1-3, 08034 Barcelona, Catalonia, Spain

${ }^{4}$ ICREA, Pg. Lluís Companys 23, 08010 Barcelona, Catalonia, Spain

${ }^{5}$ Universitat de Barcelona, Martí i Franquès, 1, 08028 Barcelona, Catalonia, Spain

*Corresponding Author: E-Mail: furbain@irec.cat

\begin{abstract}
The present study outlines the important steps to bring electrochemical conversion of carbon dioxide $\left(\mathrm{CO}_{2}\right)$ closer to commercial viability by using a large-scale metallic foam electrode as highly conductive catalyst scaffold. Due to its versatility, it was possible to specifically tailor three-dimensional copper foam through coating with silver dendrite catalysts by electrodeposition. The requirements of high yield $\mathrm{CO}_{2}$ conversion to carbon monoxide $(\mathrm{CO})$ were met by tuning the deposition parameters towards a homogeneous coverage of the copper foam with nanosized dendrites, which additionally featured crystallographic surface orientations favoring $\mathrm{CO}$ production. The presented results evidence that $\mathrm{Ag}$ dendrites, owing a high density of planes with stepped (220) surface sites, paired with the superior active surface area of the copper foam can significantly foster the $\mathrm{CO}$ productivity. In a continuous flow-cell reactor set-up, $\mathrm{CO}$ faradaic efficiencies reaching from $85 \%$ to $96 \%$ for a wide range of low applied cathode potentials $\left(<1.0 \mathrm{~V}_{\mathrm{RHE}}\right)$ along with high $\mathrm{CO}$ current densities up to $27 \mathrm{~mA} / \mathrm{cm}^{2}$ were achieved, far outperforming other tested scaffold materials. Overall, this research provides new strategic guidelines for the fabrication of efficient and versatile cathodes for $\mathrm{CO}_{2}$ conversion compatible with large-scale integrated prototype devices.
\end{abstract}

KEYWORDS: $\mathrm{CO}_{2}$ reduction, electrocatalysis, $\mathrm{CO}$ production, silver dendrites, copper foam, prototype reactor 


\section{Introduction}

Re-utilization of carbon dioxide $\left(\mathrm{CO}_{2}\right)$ is deemed as one of the key challenges to lower the atmospheric $\mathrm{CO}_{2}$ levels and steer towards a more sustainable future. In this regard, the electrochemical $\mathrm{CO}_{2}$ reduction reaction $\left(\mathrm{CO}_{2} \mathrm{RR}\right)$ comes to the fore as an alluring way to convert $\mathrm{CO}_{2}$ into fuels, chemical and materials. Simultaneously, such an electrochemical process can furthermore allow using on demand excess energy from renewable energy plants. ${ }^{1}$ However, to make this technology available at industry level, i.e. to bridge the gap between academic innovation and commercialization, versatile and cost-effective processes at large-scale are still in dire need. In addition to that, highly selective and efficient electroreduction of $\mathrm{CO}_{2}$ into value-added products is a crucial requirement. The numerous $\mathrm{CO}_{2} \mathrm{RR}$ products range from two electron products, such as carbon monoxide $(\mathrm{CO})$ and formic acid $(\mathrm{HCOOH}),{ }^{2-5}$ to multi-electron products such as methane $\left(\mathrm{CH}_{4}\right){ }^{6}$ methanol $\left(\mathrm{CH}_{3} \mathrm{OH}\right){ }^{7}$ ethylene $\left(\mathrm{C}_{2} \mathrm{H}_{4}\right),{ }^{8}$ and ethanol $\left(\mathrm{CH}_{3} \mathrm{CH}_{2} \mathrm{OH}\right){ }^{9}$ as well as other compounds. ${ }^{10}$ Due to the complex reaction pathways of $\mathrm{CO}_{2} \mathrm{RR}$, high yield selective product generation remains challenging, and, so far, has only been achieved for $\mathrm{CO}$ and formic acid in aqueous solutions. $\mathrm{CO}$ is of particular interest, as it can be efficiently separated from other reaction products (separation of liquid products is much more energy-intensive) and because together with hydrogen $\left(\mathrm{H}_{2}\right)$ it can be valorized to synthesis gas. From this versatile gas mixture, liquid transportation hydrocarbon fuels and various other value-added chemical products can be produced via the well-known and established Fischer-Tropsch synthesis. ${ }^{11}$

As reported to date, high yield and selective production of $\mathrm{CO}$ from $\mathrm{CO}_{2}$ relies on the utilization of precious metal catalysts, typically gold $(\mathrm{Au}),{ }^{12-14}$ or requires the usage of ionic liquids, ${ }^{15-17}$ which however impair the process stability. Investigating systems and processes enabling inexpensive, selective and stable $\mathrm{CO}_{2} \mathrm{RR}$ is therefore a crucial requirement for making this process economically viable, as it will be presented in this work. Furthermore, in contrast to the previous laboratory-scale systems, which only demonstrate small-scale sub-assemblies performing $\mathrm{CO}_{2} \mathrm{RR}$, we outline the important steps towards a functional and scalable process to selectively produce $\mathrm{CO}$ at large scale and high yield in neutral $\mathrm{pH}$ aqueous solution.

In particular, we propose a $\mathrm{CO}_{2} \mathrm{RR}$ cathode based on commercial and large-scale metallic foam, which was specifically adapted to meet the stringent requirements for selective $\mathrm{CO}_{2}$-to-CO conversion. Due to their three-dimensional (3D) structure, metallic foams offer the advantage of high surface area, which is necessary to circumvent the solubility limitations of $\mathrm{CO}_{2}$ gas in liquid electrolytes and thus enabling efficient $\mathrm{CO}_{2} \mathrm{RR}$ catalysis. In this regard, it is important to guarantee a high number of threephase interfaces, i.e. interfaces where $\mathrm{CO}_{2}$ gas-liquid electrolyte-solid electrode coincide. The tailoring of the 3D foam consisted firstly in the homogenous coating with optimized silver (Ag) catalysts and secondly, in the optimization of the morphological and structural characteristics of the deposited catalyst. Ag is an attractive alternative to electrodes made of $\mathrm{Au}$ for $\mathrm{CO}_{2} \mathrm{RR}$ as it exhibits similar selectivity towards $\mathrm{CO}$ under moderate overpotentials and is significantly cheaper than most other noble metals. ${ }^{18,19}$ Furthermore, nano- or microstructured Ag catalysts can lower even more the required overpotentials $^{3}$ while increasing at the same time the density of highly active sites for $\mathrm{CO}_{2} \mathrm{RR}$. In this regard, dendritic structures are of particular interest and were targeted in this study. Besides numerous examples of $\mathrm{Ag}$ based materials for $\mathrm{CO}_{2} \mathrm{RR}$ to $\mathrm{CO}$, such as nanoplates, ${ }^{20}$ nanoporous material and nanoparticles, ${ }^{21-25}$ nanowires, ${ }^{26,27}$ nanoclusters ${ }^{28}$ and porous foams, ${ }^{29}$, dendritic structures offer large active surface areas paired with facile and non-expensive synthetization. ${ }^{30-32}$ In this regard, we selected the 
electrodeposition method to deposit the Ag catalyst. On account of its functionality and cost effectiveness, this deposition process is highly viable for large-scale industrial applications, e.g. the coating of large-scale metallic foams, and therefore promising to fulfil the requirements of commercial viability. ${ }^{33-35} \mathrm{We}$ selected copper $(\mathrm{Cu})$ as the scaffold material because it is highly conductive and cost-effective paired with high technical maturity, and because $\mathrm{Cu}$ surfaces favor the growth of dendritic structures applying electrodeposition method.

This paper has a twofold purpose: to understand how the electrodeposition process can be systematically adapted in order to tailor (i) the coverage and (ii) the catalytic properties towards $\mathrm{CO}_{2} \mathrm{RR}$ of the deposited $\mathrm{Ag}$ catalyst. A complete coverage of the $\mathrm{Cu}$ foam with the $\mathrm{Ag}$ catalyst is vital to avoid $\mathrm{Cu}$ to take also part in the catalysis. The purpose of tuning the catalytic properties will be achieved by featuring crystallographic surface orientations that are conducive to selective $\mathrm{CO}$ production. Theoretical studies have proven that (110) and (220) Ag planes, respectively, particularly enhance the catalytic activity towards $\mathrm{CO}$ production. ${ }^{36}$ It was shown that these facets facilitate the activation of $\mathrm{CO}_{2}$ through a strong binding of the surface-adsorbed $* \mathrm{COOH}$ species $\left(1^{\text {st }}\right.$ reaction step) before releasing $\mathrm{CO}$ due to weak binding of the $* \mathrm{CO}$ species $\left(2^{\text {nd }}\right.$ reaction step). These findings, however, are supported only by a few experimental studies. ${ }^{30,37}$ Therefore, the present study aims to further generalize the results by employing conventional and practical methods and materials to implement the desired crystallographic orientation of the catalyst surface at an industrial scale. The herein presented results evidence that the high active surface area of the $\mathrm{Cu}$ foam paired with the optimized facet orientations of the deposited $\mathrm{Ag}$ dendrites give rise to superior $\mathrm{CO}_{2}$ conversion productivities, significantly enhancing the $\mathrm{CO}$ current density per area and mass, respectively, in comparison to other scaffold materials.

Overall the findings of this study provide a platform for the design of a highly active and selective cathode material for $\mathrm{CO}_{2}$-to- $\mathrm{CO}$ conversion which can be employed in processes at large-scale industrial scale.

\section{Experimental}

\subsection{Catalyst Deposition}

The Ag catalyst deposition was conducted by an electrodeposition process on $\mathrm{Cu}$ foam employing a conventional electrochemical three-electrode set-up (VMP3 Bio-Logic multi-channel potentiostat). A sheet of $\mathrm{Cu}$ foam with a size of $40 \times 40 \mathrm{~mm}^{2}(2.5 \mathrm{~mm}$ thick, Recemat BV Cu-4753.04, average pore diameter: $0.4 \mathrm{~mm}$ ) was used as the catalyst substrate (working electrode). Before the deposition, the foam was firstly cleaned in acetone, $2 \mathrm{M} \mathrm{HCl}$, and deionized water. For the counter electrode a platinum mesh was used and $\mathrm{Ag} / \mathrm{AgCl} / \mathrm{KCl}(3 \mathrm{M})\left(E^{0}=0.197 \quad \mathrm{~V}_{\mathrm{NHE}}\right)$ was used as reference electrode. The electrodeposition was conducted in a plating solution containing $0.1 \mathrm{M}$ $\mathrm{AgNO}_{3}, 0.5 \mathrm{M} \mathrm{NH}_{4} \mathrm{OH}$, and $0.1 \mathrm{M} \mathrm{NH}_{4} \mathrm{NO}_{3}{ }^{38}$ The cathode optimization was performed by varying the deposition parameters at ambient conditions, i.e. the applied potential and the deposition time. The last cathode preparation step consisted in rinsing of the coated $\mathrm{Cu}$ foam with deionized water and drying at room temperature. The average Ag loading on the $\mathrm{Cu}$ foam was measured by weight difference. For comparison, silver and copper foils (Alfa Aesar, 99.998\%, $0.1 \mathrm{~mm}$ thick) cathodes (with a mass of $104.9 \mathrm{~g}$ for $10 \mathrm{~cm}^{2}$ of $0.1 \mathrm{~mm} \mathrm{Ag}$ foil) and nickel (Ni) foam (1.4 mm thick, Recemat BV Ni-1116) were also employed. 


\subsection{Cathode Characterization}

Experimental details on the structural (X-ray diffraction (XRD)), morphological (scanning electron microscopy (SEM), transmission and high resolution transmission electron microscopy (TEM and HRTEM)), and compositional (electron energy loss spectroscopy (EELS)) characterization methods applied herein to analyze the asdeposited $\mathrm{Ag}$ catalyst on the $\mathrm{Cu}$ foam have been provided in Ref. 39. X-ray photoelectron spectroscopy (XPS) was applied to analyze the electronic structure of the cathode surface by using a PHI instrument model 5773 Multitechnique with A1 Ka radiation $(1486.6 \mathrm{eV})$.

The electrochemical performance of the $\mathrm{Ag}$ dendrite coated $\mathrm{Cu}$ foams towards $\mathrm{CO}_{2}$ reduction was assessed using an adapted flow cell set-up (Micro Flow Cell, Electrocell $\mathrm{A} / \mathrm{S}$ ), which is schematically depicted in Figure 1 and which was already introduced as scalable (photo)-electrochemical device in our previous works. ${ }^{39-41}$

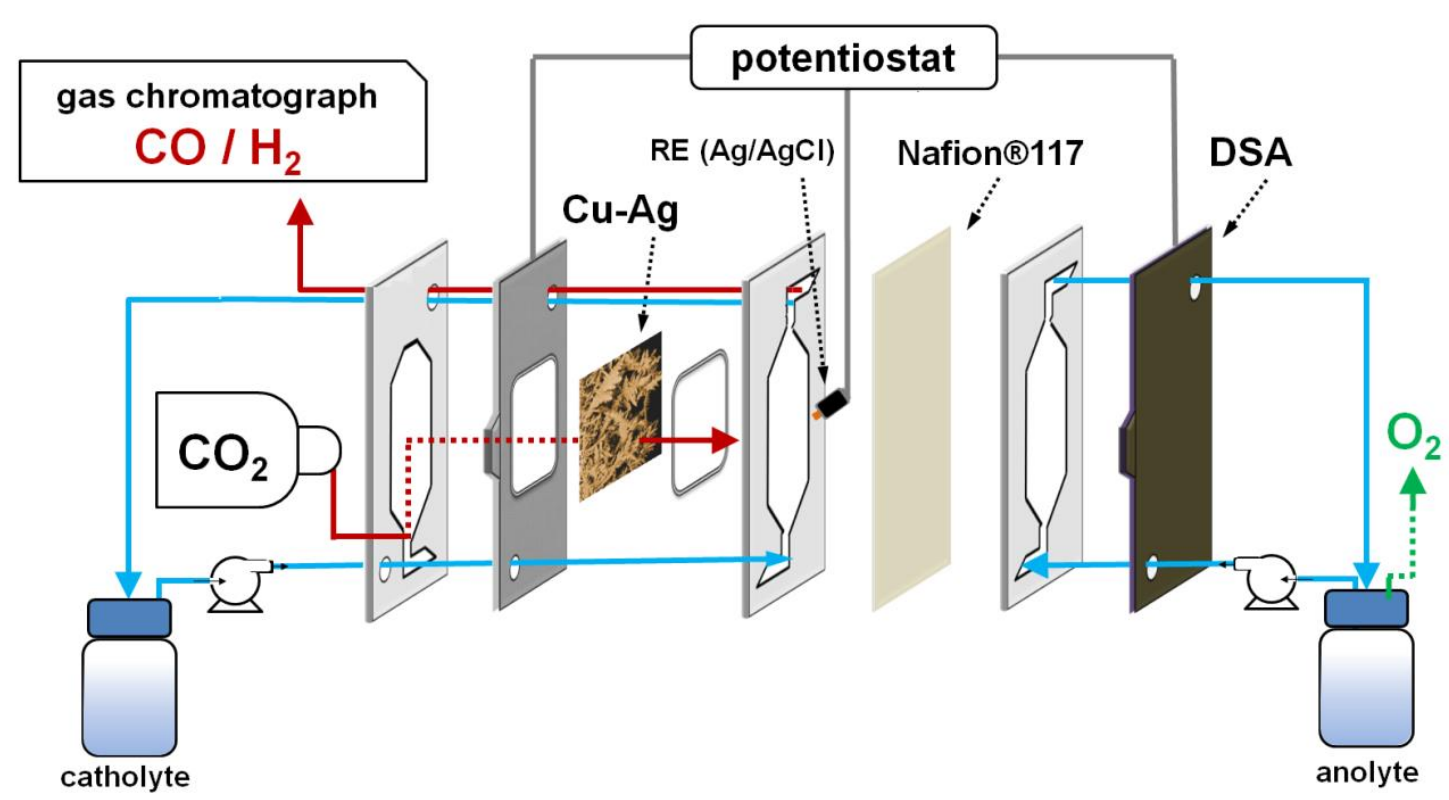

Figure 1. Sketch of the experimental set-up used to assess the $\mathrm{CO}_{2} \mathrm{RR}$ performance of the $\mathrm{Cu}$ $\mathrm{Ag}$ cathode. The set-up consisted of a filter-press flow cell with three inlets (catholyte, anolyte, and $\mathrm{CO}_{2}$ ) and two outlets (catholyte $+\mathrm{CO}_{2}$ and anolyte). Catholyte and anolyte compartments were separated by a Nafion membrane. The $\mathrm{Cu}-\mathrm{Ag}$ cathode was mounted onto a metallic holder defining a geometric surface area of the cathode of $10 \mathrm{~cm}^{2}$. The $\mathrm{CO}_{2}$ gas and electrolyte pathways within the flow cell are indicated by the red and blue arrows, respectively. A $0.5 \mathrm{M}$ $\mathrm{KHCO}_{3}$ aqueous electrolyte solution $\left(\mathrm{CO}_{2}\right.$ saturated) was used as the electrolyte. The reference electrode was a $\mathrm{Ag} / \mathrm{AgCl}(3.4 \mathrm{M} \mathrm{KCl})$ electrode and a dimensionally stable anode plate (DSA) served as counter electrode.

The flow rates of $\mathrm{CO}_{2}$ gas and electrolyte $\left(0.5 \mathrm{M} \mathrm{KHCO}_{3}\right)$, respectively, within the flow cell were kept at $20 \mathrm{ml} / \mathrm{min}$. As illustrated in Figure 1, the $\mathrm{CO}_{2}$ gas was directly introduced through the macroporous $3 \mathrm{D} \mathrm{Cu}-\mathrm{Ag}$ foam cathode (geometric surface area: $10 \mathrm{~cm}^{2}$ ). When using silver or copper foil, $\mathrm{CO}_{2}$ was flown into the catholyte solution, as the gas, in this case, could not be injected directly through the cathode, which may affect the $\mathrm{CO}_{2} \mathrm{RR}$ under operation in comparison to direct flow through the cathode. For details on the cyclic voltammetry (CV) and gas chromatography (GC) regarding the assessment of current-voltage behavior and the faradaic efficiency for gaseous $\mathrm{CO}_{2} \mathrm{RR}$ 
products, respectively, the reader is referred to Ref. 39 and the Supporting Information (SI), respectively.

\section{Results}

\subsection{Catalyst deposition and characterization}

We initiated our study with the coating of $\mathrm{Cu}$ foam substrate with Ag dendrite catalysts by means of electrodeposition. In the potentiostatic electrodeposition process, we investigated the effect of two parameters on the coating of the $\mathrm{Cu}$ foam: the deposition time and the applied potential. Figure 2 compares the morphologies of Ag coating on $\mathrm{Cu}$ foams after 15, 30, and 60 seconds at constant potentials of $-0.05,-0.2,-0.35$, and $0.5 \mathrm{~V}_{\mathrm{RHE}}$, respectively in the plating solution. At the lowest deposition potential (-0.05 $\mathrm{V}_{\mathrm{RHE}}$ ), the $\mathrm{Cu}$ foam surface was barely coated with $\mathrm{Ag}$ after $15 \mathrm{~s}$ and $30 \mathrm{~s}$, respectively. After $60 \mathrm{~s}$ a continuous film of Ag started to grow but the dendrite structure was not observed at this applied potential. The electrodeposition at $-0.2 \mathrm{~V}_{\mathrm{RHE}}$, on the contrary, led to a thin coating film with small dendrite like structures, with average dendrite sizes below $1 \mu \mathrm{m}$. However, after 15 and $30 \mathrm{~s}$ of deposition relatively large parts of the surface of the $\mathrm{Cu}$ substrate were still exposed and presumably accessible to the electrolyte. As a direct consequence, the $\mathrm{Cu}$ foam substrate, in this case, could also be active in the $\mathrm{CO}_{2} \mathrm{RR}$ catalysis, which would be to the detriment to $\mathrm{CO}_{2}$-to- $\mathrm{CO}$ conversion efficiency, because $\mathrm{Cu}$ surfaces are known to catalytically promote liquid chemicals as $\mathrm{CO}_{2}$ reduction products, such as formic acid and methanol. ${ }^{42} \mathrm{~A}$ high $\mathrm{CO}$ selectivity therefore requires an excellent coverage of the $\mathrm{Cu}$ foam with the Ag catalyst. The SEM image of the 60 seconds electrodeposition process revealed that the coverage of the foam substrate significantly augmented along with an increase of the Ag dendrite structure size. The dendrite branches ranged from $500 \mathrm{~nm}$ to $3 \mu \mathrm{m}$ (or even bigger for a few distinct structures as observable in the respective quadrant in Figure 2) featuring a highly random coating of high surface area catalyst structures, which is conducive to the exposure of more active sites for $\mathrm{CO}_{2} \mathrm{RR}$ and permeation of the catholyte. As apparent from Figure 2, the coating for $-0.35 \mathrm{~V}_{\mathrm{RHE}}$ applied potential, in average, led to bigger dendrite structures (branches and stem) for the respective deposition times. However, the coverage of the $\mathrm{Cu}$ foam seemed to be less dense compared to the one at $-0.2 \mathrm{~V}_{\mathrm{RHE}}$. Both observation were confirmed for the deposition at $-0.5 \mathrm{~V}_{\mathrm{RHE}}$, as the dendrites increased in dimension but significant portion of the $\mathrm{Cu}$ foam surface remained uncovered also after $60 \mathrm{~s}$ of deposition. This tendency was related to mass transport limitation of $\mathrm{Ag}$ ions at the electrode surface under increasing negative deposition potentials. As a result, existing dendrites continued growing, rather than new nucleation, and thus fewer dendrites appeared. Consequently, in this case, the coverage of the $\mathrm{Cu}$ foam was reduced. 


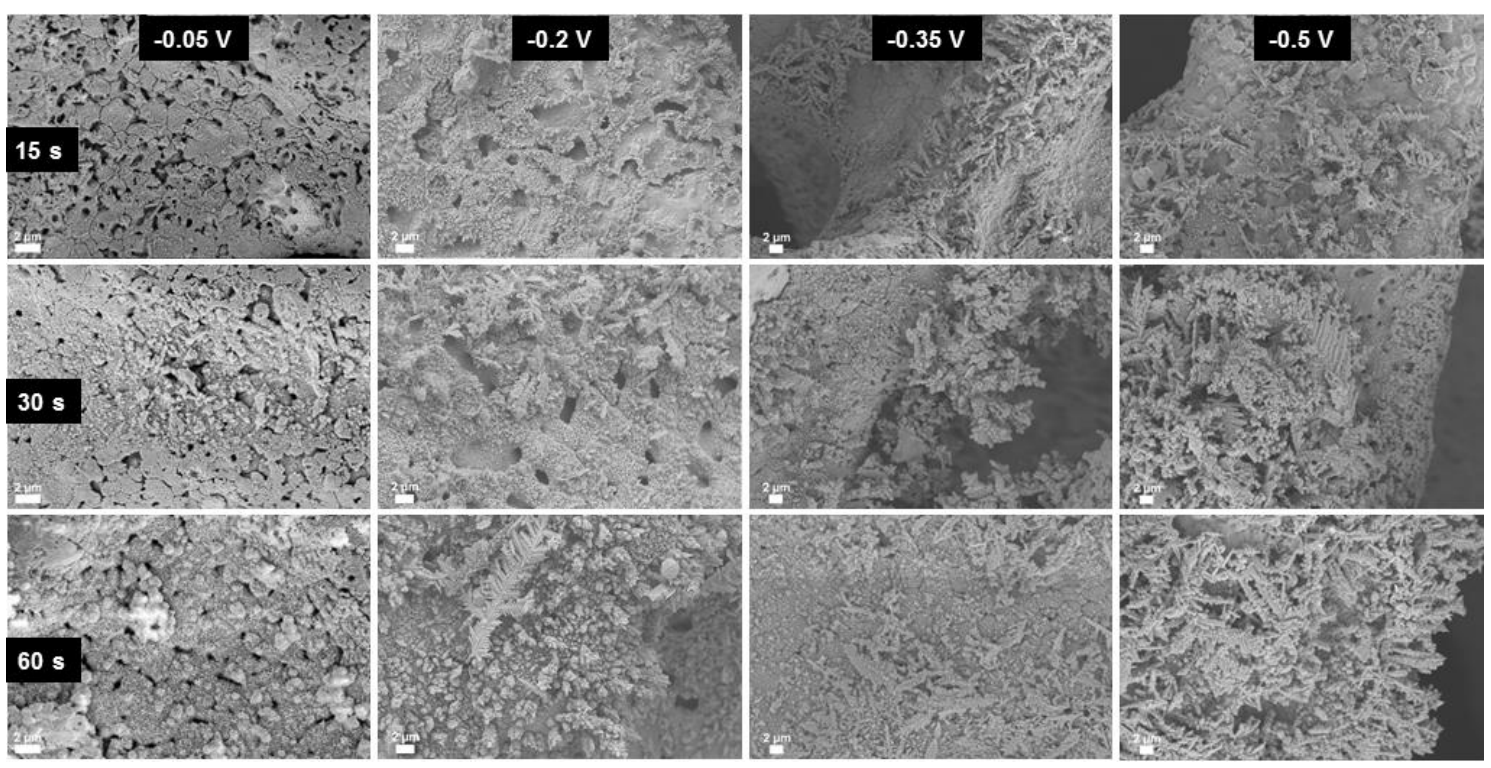

Figure 2. SEM images of the $\mathrm{Ag}$ dendrite catalyst electrodeposited on $\mathrm{Cu}$ foam for 15,30 , and 60 seconds at constant potentials of $-0.05,-0.2,-0.35$, and $-0.5 \mathrm{~V}_{\mathrm{RHE}}$, respectively in the $0.1 \mathrm{M}$ $\mathrm{AgNO}_{3}$ containing plating solution.

Besides the analysis of the morphologies, shown in Figure 2, in general it is also important to determine the active surface area of the catalyst coated scaffold. For this purpose, we estimated the electrochemical active surface area (ECSA) for one of the Ag dendrite coated $\mathrm{Cu}$ foams in comparison to the ECSA of bare $\mathrm{Cu}$ foam. In fact, the ECSA can be estimated from the electrochemical double-layer capacitance $C_{\mathrm{dl}}$ at the solid/liquid interface. ${ }^{25,27}$ The ECSA calculation process is presented in detail in the SI. From Figure $\mathrm{S} 1 \mathrm{a}$ and $\mathrm{S} 1 \mathrm{~b}$ it can be deduced that the $\mathrm{Ag}$ dendrite coated $\mathrm{Cu}$ foam cathode exhibited a higher $C_{\mathrm{dl}}$ than bare $\mathrm{Cu}$ foam, evidencing a significantly higher active surface area, which was estimated as $92.50 \mathrm{~cm}^{2}$ for the $\mathrm{Ag}$ dendrite coated $\mathrm{Cu}$ foam and $30.25 \mathrm{~cm}^{2}$ for the bare $\mathrm{Cu}$ foam (tested geometric surface area for ECSA: 2 $\left.\mathrm{cm}^{2}\right)$.

The next step in the investigation consisted in the analysis of the structural surface properties of the deposited Ag catalyst on $\mathrm{Cu}$ foam. The crystalline structure of the asdeposited Ag dendritic structures was investigated by XRD. Figure 3a exemplarily shows the XRD diffraction pattern for the sample deposited for $60 \mathrm{~s}$ at $-0.2 \mathrm{~V}$ (see Figure 2). No significant differences in the XRD measurements were detected between the other prepared samples in Figure 2. The analysis revealed that the Ag dendrite electrocatalyst mainly crystallized in the cubic phase, while a small percentage of the hexagonal phase was measured as well $(<10 \%)$. The diffraction peaks are in perfect agreement with the reference pattern for cubic Ag (JCPDS card number 00-001-1164), namely $\mathrm{Ag}(111)$ at $38.1^{\circ}, \mathrm{Ag}(200)$ at $44.3^{\circ}, \mathrm{Ag}(220)$ at $64.5^{\circ}$ and $\mathrm{Ag}(311)$ at $77.4^{\circ}$. The Ag (101) peak (*) corresponds to the hexagonal Ag phase with primitive lattice (JCPDS Card number 00-041-1402). The peaks from the $\mathrm{Cu}$ foam substrate corresponding to the $\mathrm{Cu}$ (JCPDS card number 01-070-3038) were also discernible in the diffraction pattern of the $\mathrm{Cu}-\mathrm{Ag}$ system, as expected $\left(\mathrm{Cu}(111)\right.$ at $43.2^{\circ}, \mathrm{Cu}(200)$ at $50.4^{\circ}$ and $\mathrm{Cu}(220)$ at $\left.74.1^{\circ}\right)$.

Figure $3 \mathrm{~b}$ plots the XPS spectrum of $\mathrm{Ag} 3 \mathrm{~d}_{3 / 2}$ and $\mathrm{Ag} 3 \mathrm{~d}_{5 / 2}$ double peaks from the substrate (again sample deposited for $60 \mathrm{~s}$ at $-0.2 \mathrm{~V}$ ), which were centered at 374.3 and $368.3 \mathrm{eV}$, respectively. This was in perfect agreement with those of elemental $\mathrm{Ag},{ }^{43,44}$ 
and demonstrates that there was no corrosion of $\mathrm{Ag}$ dendrites during the electrodeposition procedure.

a)

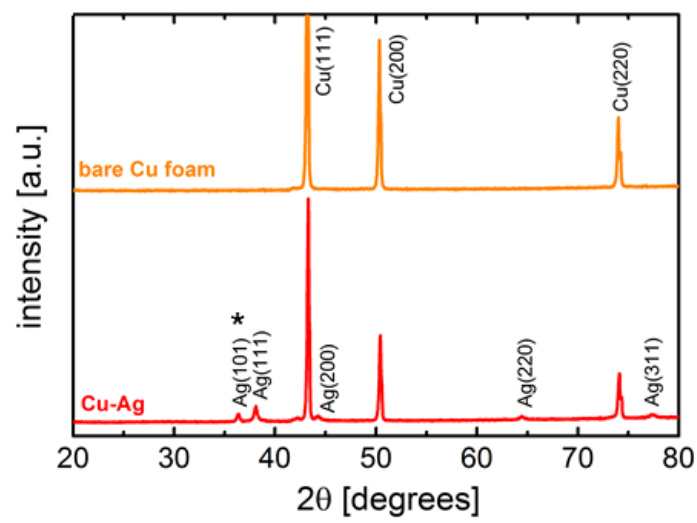

b)

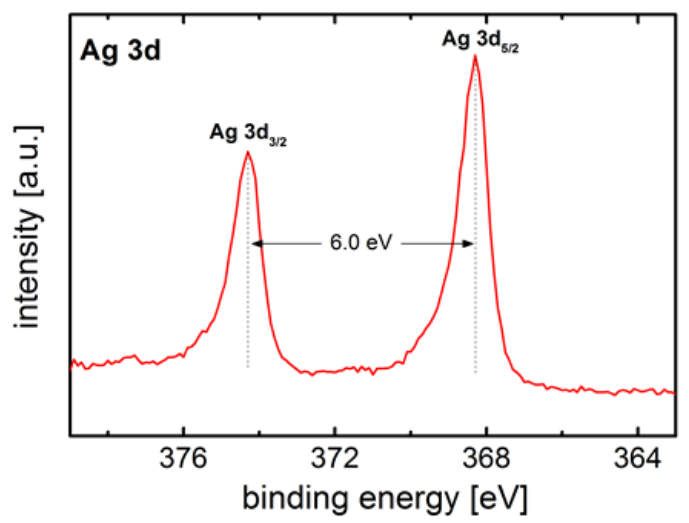

Figure 3. a) XRD measurements of the bare $\mathrm{Cu}$ foam (as reference for substrate material) and of the $\mathrm{Ag}$ coated $\mathrm{Cu}$ foam $(\mathrm{Cu}-\mathrm{Ag})$ showing signals stemming from hexagonal (*) and cubic phase $\mathrm{Ag}$ deposited at $-0.2 \mathrm{~V}$ for $60 \mathrm{~s}$. b) Respective high-resolution XPS analysis of $\mathrm{Ag} 3 \mathrm{~d}$ spectrum for the $\mathrm{Cu}-\mathrm{Ag}$ sample.

The deposited $\mathrm{Ag}$ dendrites were further investigated by means of high resolution TEM (also for sample deposited at $-0.2 \mathrm{~V}$ for $60 \mathrm{~s}$ ). Figure $4 \mathrm{a}$ displays the HRTEM image of one analyzed dendrite edge. The shape of the edge was random without sharp exposure to crystalline planes, indicating the random faceting planes of the dendrite structures. The highly crystalline feature of the Ag catalyst is persuasively depicted in Figure $4 \mathrm{~b}$. The fast Fourier transform (FFT) spectrum in Figure 4c (red squared region in Figure 4a) indicates that the edge nanostructures crystallized in the Ag cubic phase. The XRD measurement (Figure 3a), however, also identified a small hexagonal phase contribution. In this regard, Figure S2a in the SI shows the HRTEM image of a different dendrite edge, from which a polytypic behavior is observable. In these dendrites, periphery regions could be detected that presented many defects, such as twins and stacking faults. The FFT of Figure S2b furthermore reveals that there were two sets of diffraction patterns from the twinning domains (cubic), which shared the same planes of \{1-11\} (indicated by the white arrow in Figure S2a). The presence of a high density of twins, as those reported in Figure S2a, may induce the formation of polytypic structures, with alternating cubic and hexagonal domains in the nanostructure, as already typically observed in semiconductor nanostructures (e.g. $\mathrm{Si},{ }^{45} \mathrm{GaAs},{ }^{46} \mathrm{ZnTe},{ }^{47}$ ). In fact, this could be the origin of the cubic and hexagonal signals observed in the XRD patterns (Figure 3a). 


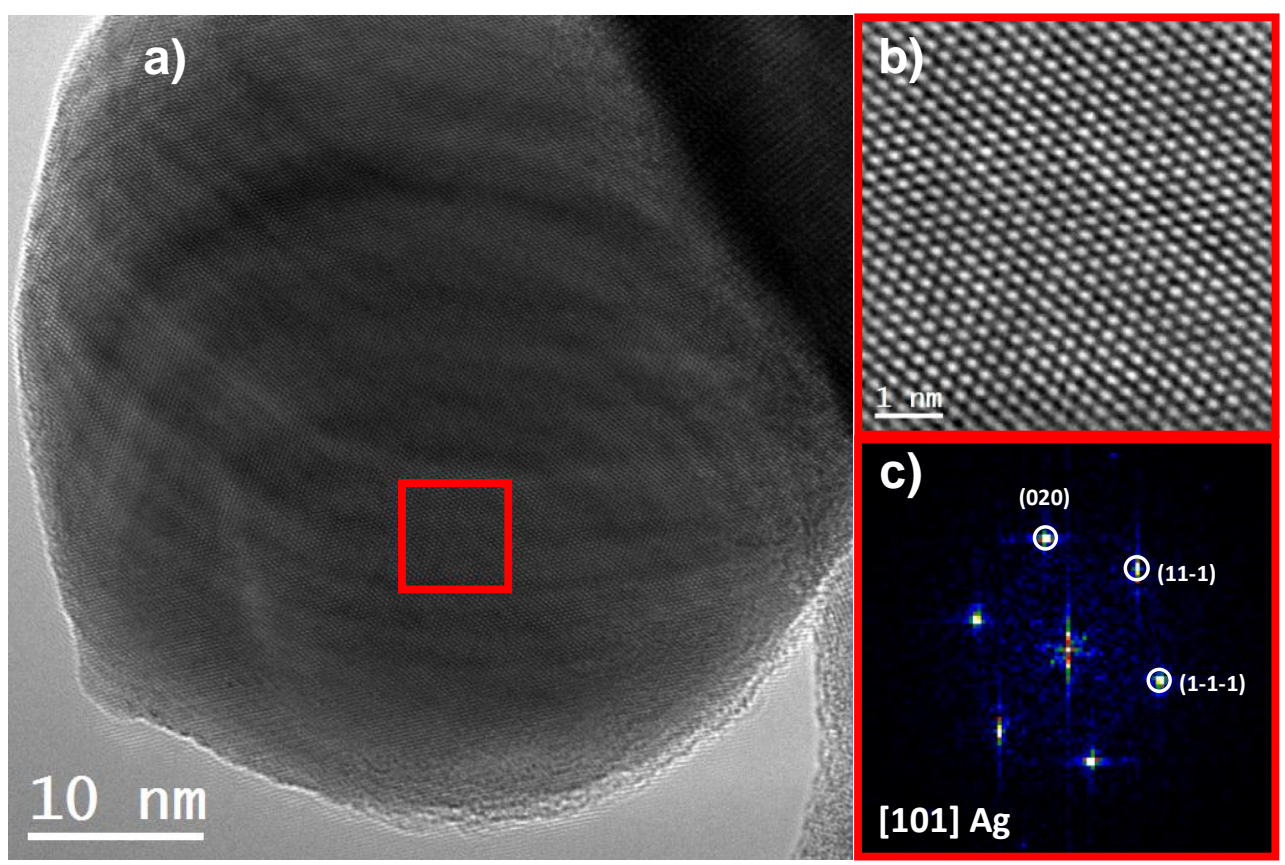

Figure 4. a) HRTEM image of the edge of a dendrite branch showing its structural distribution. b) HRTEM detail of the red marked region in a). c) The corresponding temperature colored FFT spectrum of the red squared region indicating that the material in the dendrite branch crystallizes in the cubic Ag phase, [FM3M]-Space group 225, with lattice parameters of $\mathrm{a}=\mathrm{b}=\mathrm{c}=0.4164$ $\mathrm{nm}$, and $\alpha=\beta=\gamma=90^{\circ}$ as visualized along the [101] direction.

The crystallographic orientation of the dendritic structures was assessed hereafter. The low magnification view of the $\mathrm{Ag}-\mathrm{Cu}$ foam samples in Figure 5a shows the dendritic structure comprising the stem and the dendrite branches. As apparent from Figure 5a), the branches followed $\langle 111\rangle$ directions and an angle between the stem and the branches of $109.5^{\circ}$ could be measured. This implies that the stem of the Ag dendrites grew along the [001] direction. Based on this finding and based on the FFT result shown in Figure $\mathrm{S} 2 \mathrm{~b}$, a simulated diffraction pattern (inset in Figure 5a) could be deduced. This information allowed performing a simulated scale model of the $\mathrm{Ag}$ dendrite branch along the [1-11] growth direction, shown in Figure 5b. and Figure 5c, respectively. The illustration nicely depicts the dendritic shape along with the main and secondary surface facet types, $\{110\}$ and $\{112\}$, respectively (Figure 5d). Such facetrich structures can boost the $\mathrm{CO}_{2}$-to- $\mathrm{CO}$ conversion rates, as shown previously for $\mathrm{Ag}$ and $\mathrm{Au}$ nanostructures, respectively, and thus, are of particular interest for the herein targeted CO production. ${ }^{20,48,49}$
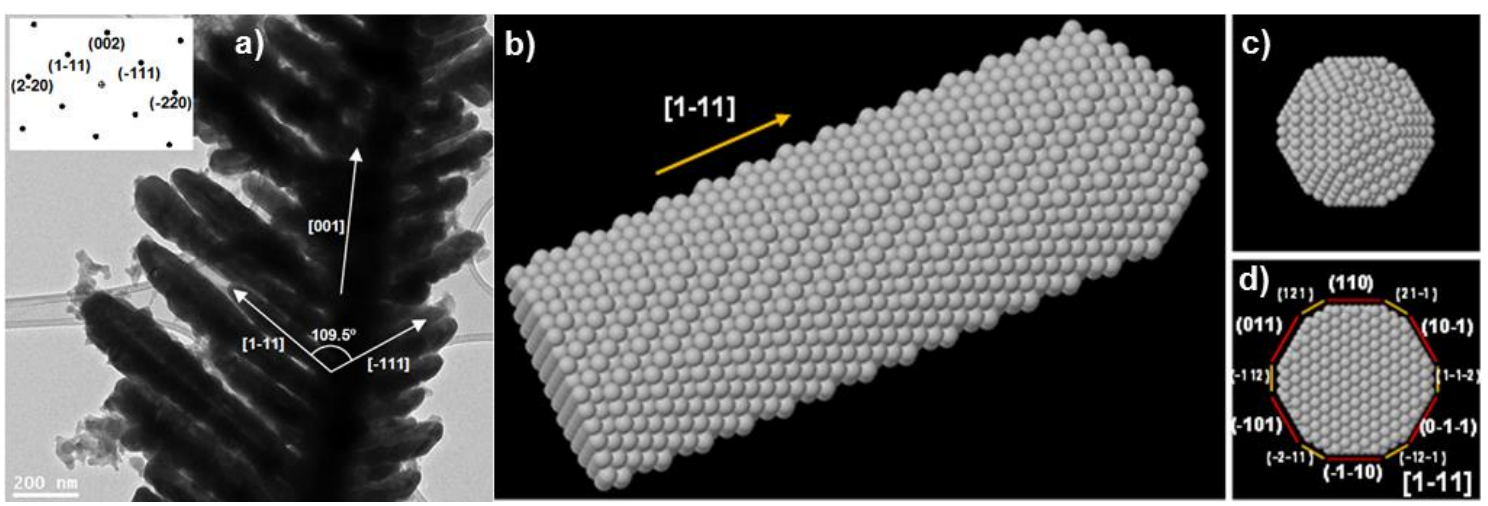
Figure 5. a) Low magnification TEM image of the $\mathrm{Ag}-\mathrm{Cu}$ foam sample showing the dendritic shape with the crystal directions labeled. The inset corresponds to a simulated diffraction pattern in agreement with the FFT results shown in Figure S2b. b) Simulated scaled model of an Ag dendritic branch along the [1-11] growth direction, as found by HRTEM. c) Front view of the dendrite branch showing the rounded tip terminated in a (1-11) facet. d) Dendrite branch cross section showing the lateral facets, with main $\{110\}$-type surfaces (marked in red) and secondary $\{112\}$-type facets (marked in yellow).

To investigate the dendrite structural composition in more detail, EELS spectrum images (compositional maps) were obtained at the nanoscale. The acquired composition map of an Ag dendrite branch is shown in Figure 6. The analysis evidenced that the dendrite branches were mainly composed of crystalline Ag, which dominated the core part of the catalyst structures. In the thin periphery region, oxygen, copper, and carbon were detected. The latter element was detected as residual from the hexane dispersion solution (see Experimental 2.2), while $\mathrm{Cu}$ may have occurred from the residual of $\mathrm{Cu}$ foam in the dispersion solution used for the TEM measurements (see Experimental 2.2). The evidenced oxygen is supposed to stem from the oxidation of copper and carbon residuals because the crystalline $\mathrm{Ag}$ dominates the dendritic matrix based on the HRTEM characterization. Therefore, we can assume that the residual induced periphery layer (down right in Figure 6) was not present in the as-deposited Ag catalyst structure, and thus would not affect the electrochemical characterization.
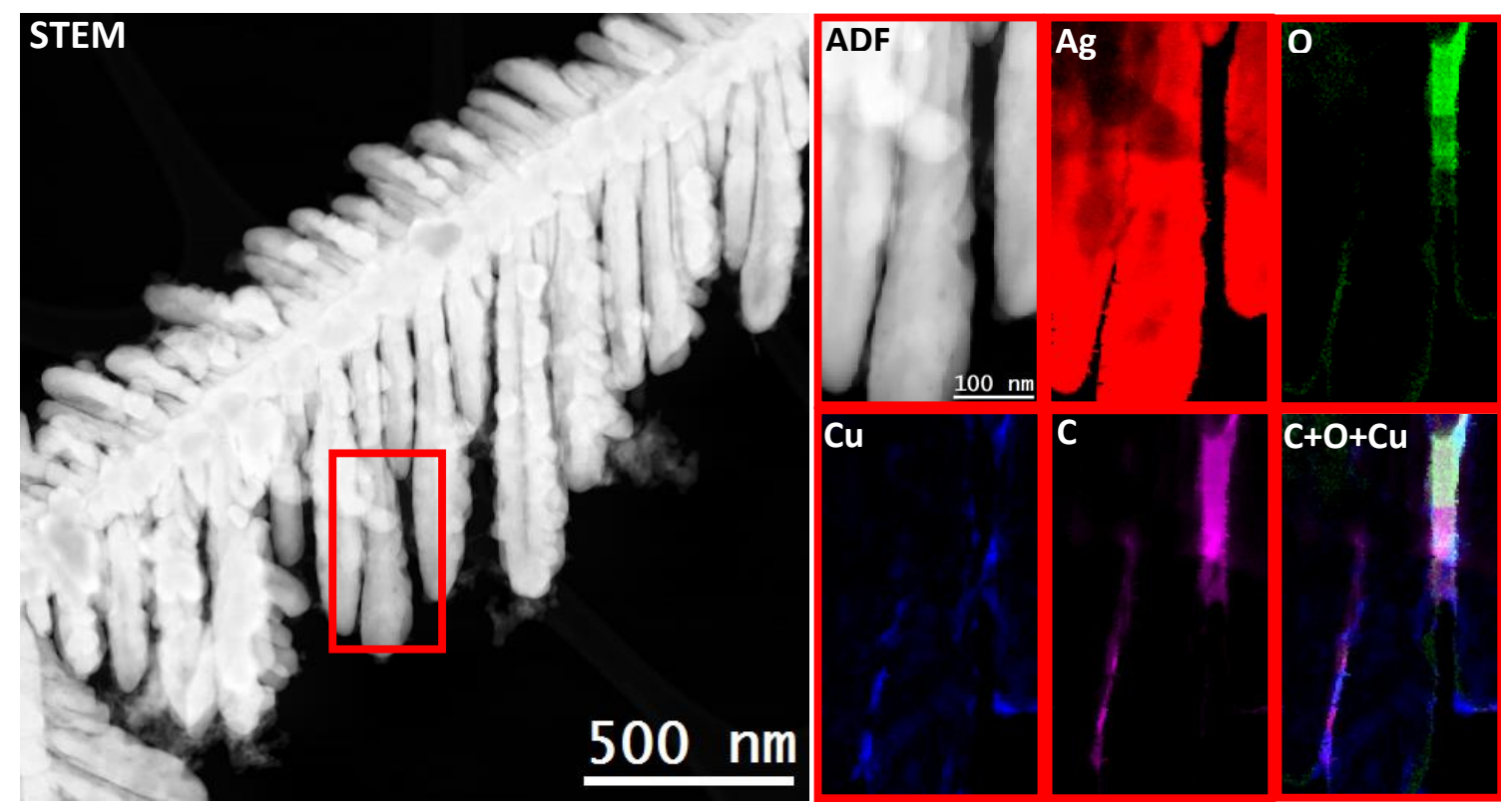

Figure 6. Left: General annular dark field (ADF) STEM image of a dendrite branch. Right: Nanoscale EELS chemical composition maps obtained from the red rectangled area on the ADF-STEM micrograph. Individual Ag (red), O (green), $\mathrm{Cu}$ (blue), $\mathrm{C}$ (pink) maps and their composite.

\subsection{Electrochemical reduction of $\mathrm{CO}_{2}$}

The electrochemical performance of the $\mathrm{Cu}-\mathrm{Ag}$ cathodes regarding $\mathrm{CO}_{2} \mathrm{RR}$ was assessed in the electrochemical flow cell (three-electrode configuration), as shown in Figure 1. A commonly employed $0.5 \mathrm{M} \mathrm{KHCO}_{3}$ aqueous electrolyte solution saturated with $\mathrm{CO}_{2}(\mathrm{pH}=7.5)$ was used as catholyte. ${ }^{21,24,26,29}$ The fluidic characteristics of the employed cell design allowed to recirculate the catholyte solution (flow rate of 20 $\mathrm{ml} / \mathrm{min}$ ), while the $\mathrm{CO}_{2}$ gas was directly injected through the macroporous $3 \mathrm{D} \mathrm{Cu}-\mathrm{Ag}$ 
cathode. Such continuous-flow operation designs allow alleviating mass transport limitations for $\mathrm{CO}_{2} \mathrm{RR}$ catalysis and thus improving partial current densities of reaction products, as shown by Kenis et al. and Newman et al. ${ }^{50,51}$ In one of our prior studies, we identified a gas-to-electrolyte flow ratio of 1 as optimum for the flow reactor design, which is why we also employed this ratio in the present study. In particular, it was verified that a ratio of 1 ensures the perfect balance between offering the right amount of catholyte and $\mathrm{CO}_{2}$ gas at the cathode surface. ${ }^{40}$

Figure 7 depicts the faradaic efficiencies at different potentials achieved with the $\mathrm{Cu}$ foam cathode prepared at $-0.2 \mathrm{~V}_{\mathrm{RHE}}$ for 15, 30, and $60 \mathrm{~s}$ electrodeposition of Ag. An electrodeposition time of 0 seconds refers to bare $\mathrm{Cu}$ foam. The calculation of the faradaic efficiencies of $\mathrm{CO}$ and $\mathrm{H}_{2}$ is described in detail in the SI.
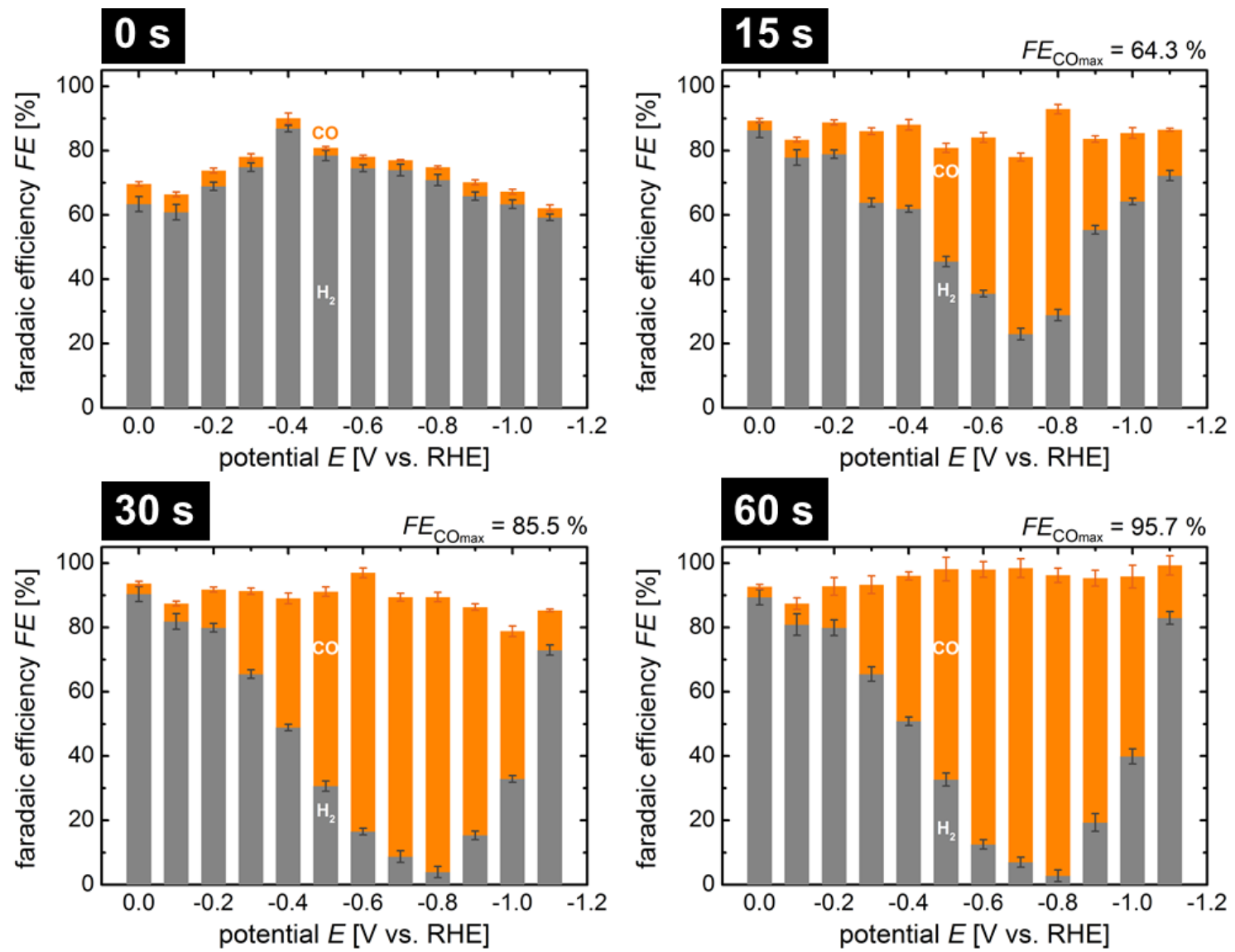

$60 \mathrm{~s}$

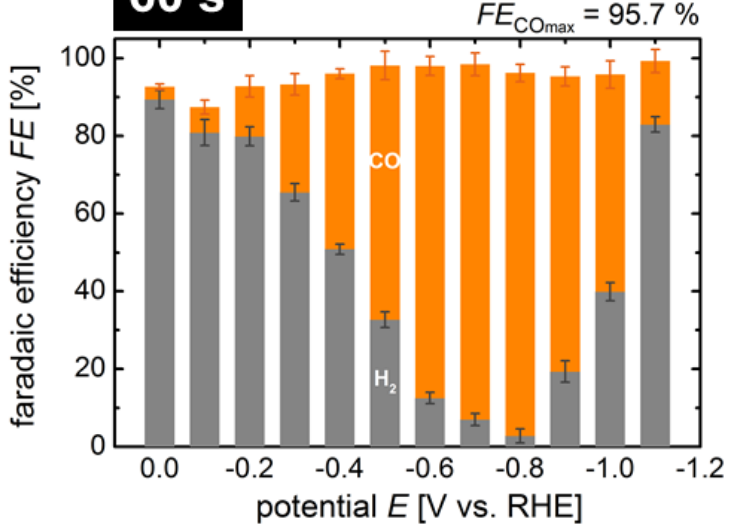

Figure 7. Faradaic efficiencies of $\mathrm{CO}$ and $\mathrm{H}_{2}$ production as a function of the applied potential for the cathodes prepared at $-0.2 \mathrm{~V}_{\mathrm{RHE}}$ (see Figure 2) with the according Ag electrodeposition time indicated. The error bars indicate standard deviations obtained from 2 experimental repeats. A flow rate of $20 \mathrm{ml} / \mathrm{min}$ was applied for the $\mathrm{CO}_{2}$ and electrolyte flow, respectively. The respective maximum $\mathrm{CO}$ faradaic efficiencies for $\mathrm{Ag}$ dendrite coated $\mathrm{Cu}$ foam cathodes are indicated above the insets.

As expected, the bare $\mathrm{Cu}$ foam surface ( 0 seconds of electrodeposition time) did not promote the generation of $\mathrm{CO}$. The data shows that $\mathrm{H}_{2}$ was the major detected gaseous product with a maximum faradaic efficiency of $87.8 \%$ at $-0.4 \mathrm{~V}_{\mathrm{RHE}}$. The selectivity for $\mathrm{CO}$ production was below $5 \%$ for the entire investigated potential range and the total faradaic efficiency for $\mathrm{CO}$ and $\mathrm{H}_{2}$ ranged between $61 \%$ and $91 \%$. This suggested the formation of other products (not measured here), for instance formic acid, as already reported elsewhere. ${ }^{42}$ 
The thin coating film provided after 15 seconds of electrodeposition immensely affected the catalytic behavior of the tested cathode, as the selectivity towards $\mathrm{CO}$ products drastically increased (Figure 7, upper right). The $\mathrm{CO}$ faradaic efficiency significantly augmented for the majority of the investigated potentials from around $5 \%$ without $\mathrm{Ag}$ dendrites $(0 \mathrm{~s})$ to a maximum value of $64.3 \%$ at $-0.8 \mathrm{~V}_{\mathrm{RHE}}$ for the Ag dendrite coated $\mathrm{Cu}$ foam cathode $(15 \mathrm{~s})$. However, the total faradaic efficiency remained between $81 \%$ and $90 \%$ for the different potentials, suggesting that the uncovered $\mathrm{Cu}$ foam areas take part in the $\mathrm{CO}_{2} \mathrm{RR}$ catalysis to produce other products (as expected and shown in Ref. 42). A more dense coverage of the $\mathrm{Cu}$ foam including increased dendrite structures, which was obvious after 30 seconds of electrodeposition (see Figure 2 for $-0.2 V_{\text {RHE}}$ ), further drastically increased the selectivity towards $\mathrm{CO}$ formation, as can be seen from the lower left plot in Figure 7, with a maximum faradaic efficiency of $85.5 \%$ (at -0.8 $\mathrm{V}_{\mathrm{RHE}}$ ). This entails that the total faradaic efficiency for $\mathrm{CO}$ and $\mathrm{H}_{2}$ surpassed $90 \%$ for the majority of the investigated potentials and reached values up to $97 \%$. The best selectivity for $\mathrm{CO}$ and $\mathrm{H}_{2}$ was however exhibited by the cathode prepared for $60 \mathrm{~s}$ (at $0.2 \mathrm{~V}_{\mathrm{RHE}}$, Figure 2). As apparent from the lower right graph in Figure 7, CO production was amplified for all investigated potentials, especially in the potential range between 0.4 and $-1.1 \mathrm{~V}_{\mathrm{RHE}}$. In this range, total $\mathrm{CO} / \mathrm{H}_{2}$ faradaic efficiencies close to $100 \%$ were measured along with a maximum $\mathrm{CO}$ faradaic efficiency of $95.7 \%$ at $-0.8 \mathrm{~V}_{\mathrm{RHE}}$ applied bias, implying an excellent coverage of the $\mathrm{Cu}$ foam with the $\mathrm{Ag}$ dendritic catalyst. For lower potentials $\left(<-0.4 \mathrm{~V}_{\mathrm{RHE}}\right)$ we expect the formation of low amounts of liquid products (not measured here), as already reported elsewhere for $\mathrm{Ag}$ catalysts. $^{29}$ Deposition times beyond $60 \mathrm{~s}$ were also considered in this study. In the SI, the morphology and the faradaic efficiency of the $\mathrm{Cu}$ foam cathode, respectively, after 2 and 3 min of electrodeposition are shown (Figure S3). As apparent the coating of the 3D foam was highly dense in both cases. Additionally the overall selectivity towards gas production $\left(\mathrm{CO}+\mathrm{H}_{2}\right)$ slightly increased, and reached nearly $100 \%$ faradaic efficiency in the investigated potential range. However, the maximum faradaic efficiency for the targeted CO (in both cases at $-0.8 \mathrm{~V}_{\mathrm{RHE}}$ ) could not be augmented (94.7\% and $92.3 \%$, respectively).

Figure 8 depicts the maximum $\mathrm{CO}$ faradaic efficiency $\left(F E_{\mathrm{CO}}\right)$ as a function of the electrodeposition time and the applied potential in the potentiostatic process for all investigated samples (shown in Figure 2). This graph enables to examine the impact of the complete set of parameters on the catalytic performance studied in this work. The values for maximum faradaic efficiency in Figure 8 were acquired at $-0.8 \mathrm{~V}_{\mathrm{RHE}}$, as the highest $\mathrm{CO}$ selectivity was detected at this cathodic potential for the samples deposited at $-0.2 \mathrm{~V}$ (see Figure 7). From Figure 8 it becomes obvious that, except for the $-0.05 \mathrm{~V}$ samples (grey triangles), deposition times beyond $60 \mathrm{~s}$ could not lead to higher maximum $\mathrm{CO}$ selectivities. The values for $F E_{\mathrm{CO}}$ did not increase (even decreased slightly) for longer deposition times for the cathodes deposited at -0.2 (black squares), 0.35 (purple circles), and $-0.5 \mathrm{~V}_{\mathrm{RHE}}$ (blue diamonds), respectively. This observation suggests that after $60 \mathrm{~s}$ no new nucleation could start (because of complete coverage or ion diffusion limitation) and that prolonged deposition times solely increased the dendrite dimensions. Hence the CO selectivity was slightly impaired, as it is well accepted that nano/microsized catalysts propel catalytic activities more than macroscopic structures. ${ }^{3}$

We therefore concluded that plating processes longer than $60 \mathrm{~s}$ are not beneficial for this process with respect to high CO selectivity. Moreover, this result was in line with the aim to minimize process time and loaded catalyst material in view of large scale commercial application. The highest faradaic efficiency measured in this study was 95.7 
$\%$ for the $\mathrm{Cu}-\mathrm{Ag}$ cathode deposited at $-0.2 \mathrm{~V}$ for $60 \mathrm{~s}$. Furthermore, our flow cell device design allows for advanced flow dynamics, which results in lower potentials to reach such high selectivity compared to related $\mathrm{CO}_{2} \mathrm{RR}$ systems. To estimate

In the following we focus on the comparison of $\mathrm{Cu}$ foam with other catalyst substrates, such as foils of $\mathrm{Cu}$ and $\mathrm{Ag}$ and $\mathrm{Ni}$ foam. By checking $\mathrm{Cu}$ foam against other catalyst scaffolds, we expect to gain a better understanding of the catalytic activity towards $\mathrm{CO}_{2} \mathrm{RR}$, especially regarding the effect of the deposited catalyst morphology and structure.

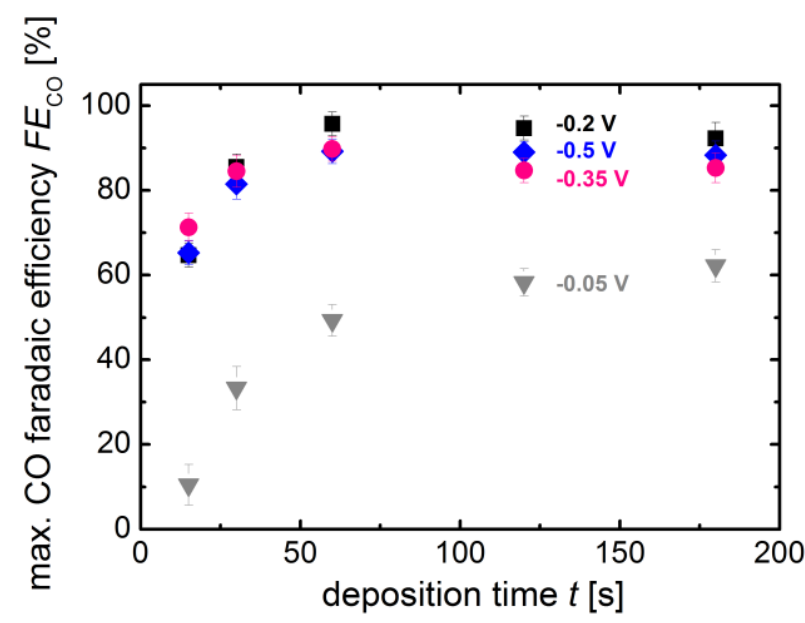

Figure 8. Maximum faradaic efficiency for $\mathrm{CO}$ production as a function of the deposition time and the applied potentials during the potentiostatic electrodeposition process. The error bars indicate standard deviations obtained from 2 experimental repeats. A flow rate of $20 \mathrm{ml} / \mathrm{min}$ was applied for the $\mathrm{CO}_{2}$ and electrolyte flow, respectively. The values were acquired at an applied potential of $-0.8 \mathrm{~V}_{\text {RHE }}$.

\subsection{Comparison of $\mathrm{Cu}$ Foam with Other Substrates}

Figure 9a represents the cyclic voltammogram of the champion $\mathrm{Cu}$ foam based cathode (deposited at $-0.2 \mathrm{~V}$ for $60 \mathrm{~s}$ ) from Figure 7 and Figure 8 (black curve). For comparison, the same measurement was also conducted for a flat $\mathrm{Cu}$ foil with $\mathrm{Ag}$ catalyst (green curve) and a flat $\mathrm{Ag}$ foil cathode (orange curve). The $\mathrm{Cu}$ foil sample was coated with $\mathrm{Ag}$ employing the same electrodeposition process as for the $\mathrm{Cu}$ foam cathode. As apparent from the SEM image shown in the SI, in Figure S4a and S4b, the same deposition process did not lead to the growth of dendritic structures on $\mathrm{Cu}$ foil, but to Ag agglomerates. Fluctuations in the CV curves may stem from the characteristics of the used flow-reactor set-up. 

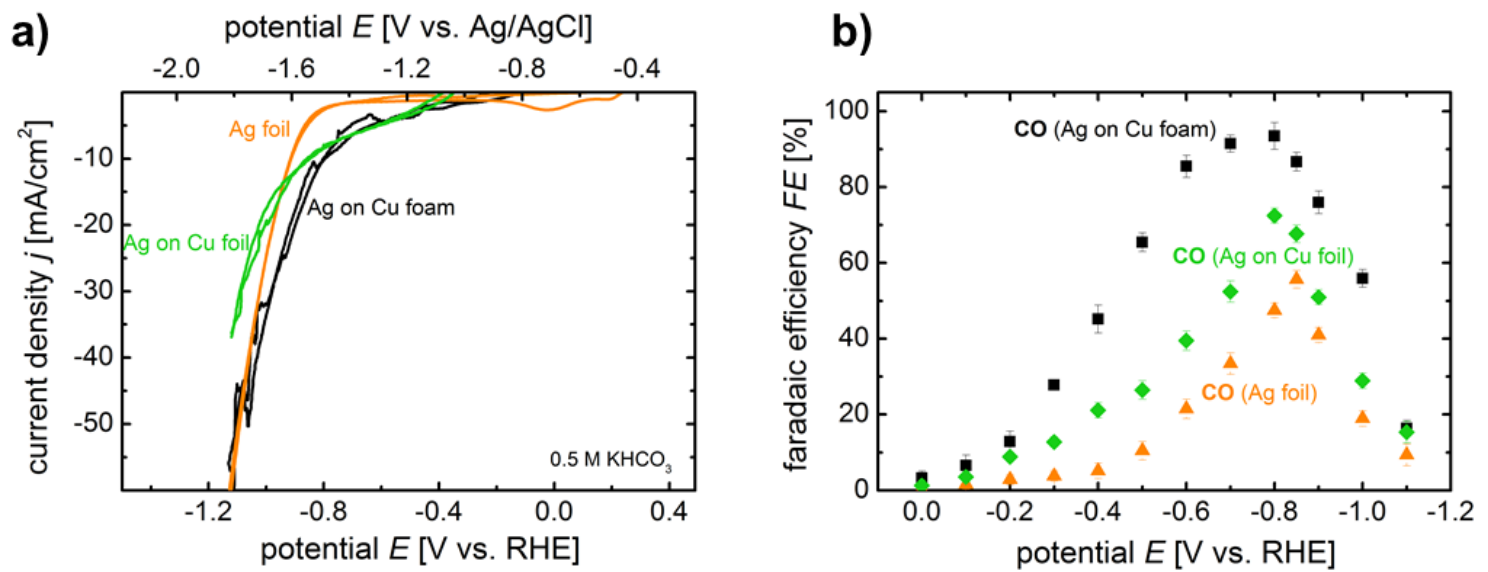

Figure 9. a) Cyclic voltammetry measurements of the $\mathrm{Ag}$ dendrite coated $\mathrm{Cu}$ foam cathode (black curve). For comparison the $\mathrm{CV}$ measurements of an $\mathrm{Ag}$ foil (orange curve) and a $\mathrm{Cu}$ foil coated with $\mathrm{Ag}$ (green curve, same $\mathrm{Ag}$ deposition parameters as for the $\mathrm{Cu}$ foam). All the measurements were conducted in $0.5 \mathrm{M} \mathrm{KHCO}_{3}$ at a scan rate of $10 \mathrm{mV} / \mathrm{s}$. The current densities are based on geometric cathode surface areas $\left(10 \mathrm{~cm}^{2}\right)$. The steady state CVs were obtained after three cycles. b) Faradaic efficiencies of $\mathrm{CO}$ for the Ag dendrite catalyst coated $\mathrm{Cu}$ foam cathode (black squares), for the $\mathrm{Ag}$ foil cathode (orange triangles) and for the $\mathrm{Cu}$ foil cathode (green diamonds) at different potentials. For the $\mathrm{Ag}$ and $\mathrm{Cu}$ foil electrodes, $\mathrm{CO}_{2}$ was bubbled in the catholyte solution (see Section 2). The error bars indicate standard deviations obtained from 2 experimental repeats. A flow rate of $20 \mathrm{ml} / \mathrm{min}$ was applied for $\mathrm{CO}_{2}$ and electrolyte flow, respectively. The corresponding faradaic efficiencies of $\mathrm{H}_{2}$ for the investigated samples are shown in Figure S6 in the SI.

For the Ag foil, it can be seen from Figure 9a that no evident voltammetric response was detected before the potential $-0.6 \mathrm{~V}_{\mathrm{RHE}}$, indicating the negligible $\mathrm{CO}_{2} \mathrm{RR}$ activity. Inversely, the $\mathrm{CO}_{2} \mathrm{RR}$ current of the $\mathrm{Ag}$ dendrite coated $\mathrm{Cu}$ foam appeared at the earliest potential of $-0.3 \mathrm{~V}_{\mathrm{RHE}}$ owing to its large catalytically active $3 \mathrm{D}$ surface and the direct injection of gaseous $\mathrm{CO}_{2}$ at the cathode surface, which favors the $\mathrm{CO}_{2} \mathrm{RR}$ kinetics. The onset potential measured for the $\mathrm{Cu}$ foil coated with the $\mathrm{Ag}$ agglomerates was around $0.4 \mathrm{~V}_{\text {RHE}}$. From Figure 9a it can therefore be concluded that the performance of the Ag coated $\mathrm{Cu}$ foam cathode exceeded the performance of the $\mathrm{Ag}$ foil and $\mathrm{Cu}-\mathrm{Ag}$ foil regarding $\mathrm{CO}_{2} \mathrm{RR}$ current density in the entire investigated potential range from 0 to $1.0 \mathrm{~V}_{\mathrm{RHE}}$. Only for potentials above $-1.0 \mathrm{~V}_{\mathrm{RHE}}$ the $\mathrm{Ag}$ foil and $\mathrm{Cu}-\mathrm{Ag}$ foam cathode provided similar current densities. The superior electrochemical performance of the $\mathrm{Ag}$ coated $\mathrm{Cu}$ foam cathode regarding $\mathrm{CO}_{2} \mathrm{RR}$ was further evidenced by comparing the performance of the sample measured under pure argon (Ar) flow. As apparent from Figure S5, the cathode performance was significantly enhanced under $\mathrm{CO}_{2}$ flow compared to Ar flow, regarding onset potential for cathodic current and high current densities.

Following the $\mathrm{CV}$ measurement, we subsequently assessed the $\mathrm{CO}_{2} \mathrm{RR}$ selectivity of the $\mathrm{Cu}-\mathrm{Ag}$ foam cathode and of the two other electrodes towards reaction products using gas chromatography. Figure $9 \mathrm{~b}$ displays the measured faradaic efficiencies for $\mathrm{CO}$ which were already presented in Figure 7 for the 60 s sample. $\mathrm{CO}$ and $\mathrm{H}_{2}$ partial current densities of the $\mathrm{CO}_{2} \mathrm{RR}$ are plotted in Figure S7. As already apparent from Figure 7 (for $60 \mathrm{~s}$ ), a very high selectivity for the generation of the two gaseous products $\mathrm{CO}$ and $\mathrm{H}_{2}$ was exhibited from the $\mathrm{Cu}-\mathrm{Ag}$ foam cathode (total faradaic efficiency close to $100 \%$ for potentials from 0 to $-1.1 \mathrm{~V}_{\mathrm{RHE}}$, see Figure $9 \mathrm{~b}$ and Figure $\mathrm{S} 6$ ). At the highest faradaic efficiency of $\mathrm{CO}$ of $95.7 \%$ (at $-0.8 \mathrm{~V}_{\mathrm{RHE}}$ ) this cathode exhibited an eminent $\mathrm{CO}$ current density of $9.5 \mathrm{~mA} / \mathrm{cm}^{2}$ (Figure S7). A maximum CO partial current density of 27.3 
$\mathrm{mA} / \mathrm{cm}^{2}$ was measured at $-1.0 \mathrm{~V}_{\mathrm{RHE}}$. Further increase in applied potential did not result in higher $\mathrm{CO}$ yield because mostly $\mathrm{H}_{2}$ formation was promoted (see black squares in Figure S6). Similar observations in other reports were assigned to mass transport limitations of $\mathrm{CO}_{2}$ at high current densities and not to the intrinsic activity of the $\mathrm{Ag}$ catalysts. $^{19,52}$ Nevertheless, the herein demonstrated $\mathrm{CO}$ production yield (at low potentials $<-1.0 \mathrm{~V}_{\mathrm{RHE}}$ ) surpasses the performance of $\mathrm{Ag}$ dendrite and other $\mathrm{Ag}$ based systems for $\mathrm{CO}_{2} \mathrm{RR}$ at ambient conditions. ${ }^{20,29,30,51,53,54}$ Therefore, our findings clearly demonstrate the superior electrochemical characteristics of the presented metallic foam supported cathode.

Figure $9 \mathrm{~b}$ furthermore provides evidence that the $\mathrm{Ag}$ dendrite based foam cathode outperformed the $\mathrm{Ag}$ and $\mathrm{Cu}$ foil scaffold cathode with respect to selectivity for $\mathrm{CO}$ production. The $\mathrm{CO}$ faradaic efficiencies measured for the $\mathrm{Ag}$ foil (orange triangles) and $\mathrm{Cu}$ foil (green diamonds), respectively, were below the values of the $\mathrm{Cu}$-Ag cathode (black squares) in the entire investigated potential range with an inferior maximum faradaic efficiency of $55.7 \%$ and $72.5 \%$, respectively (both at $-0.8 \mathrm{~V}_{\mathrm{RHE}}$ ). Notably from Figure $9 \mathrm{~b}$, the $\mathrm{CO}$ selectivity of the $\mathrm{Cu}$ foam based cathode also started to augment at lower potentials than for the $\mathrm{Ag}$ and $\mathrm{Cu}$ foil based cathodes, respectively. This behavior exactly mirrors the respective CV curves in Figure 9a, i.e. the shift in the onset potentials for $\mathrm{CO}_{2} \mathrm{RR}$ of both tested cathodes. In fact, the enhanced $\mathrm{CO}_{2} \mathrm{RR}$ catalytic activity can be ascribed to the combination of nano/microsized dendrites with the 3D macroporous structure of the supporting $\mathrm{Cu}$ foam itself. This marriage resulted in a significantly increased contact area between catalysts and electrolytes and provided a greater amount of active sites where $\mathrm{CO}_{2} \mathrm{RR}$ could take place (see ECSA estimation in the SI, Figure S1). Furthermore, the flow cell design of the applied reactor ensured an improved transport of reactants $\left(\mathrm{CO}_{2}\right.$ and electrolyte) and products $\left(\mathrm{CO}\right.$ and $\left.\mathrm{H}_{2}\right)$. Moreover, the presented $\mathrm{Ag}$ dendrite catalyst offers distinct advantages regarding large scale applications due to its facile deposition and high catalytic performance in delivering significantly higher (4 orders of magnitude) mass specific CO current density than flat $\mathrm{Ag}$ foil (see corresponding plot in Figure S8).

Besides CV and GC data, another crucial parameter of electrocatalytic activity is the corresponding Tafel slope. In Figure 10 the logarithm of the CO partial current density is plotted against the potential of the $\mathrm{Ag}$ dendrite coated $\mathrm{Cu}$ foam and $\mathrm{Ag}$ foil cathode. The Tafel slope is acquired from the range of linearity at the low-voltage scope. As listed in Figure 10, in this region, the Tafel slope of $\mathrm{Cu}-\mathrm{Ag}$ cathode was $89.7 \mathrm{mV} / \mathrm{dec}$, and thus, as expected, much lower than $\mathrm{Ag}$ foil $(198.7 \mathrm{mV} / \mathrm{dec})$ and also lower compared to other Ag structures for $\mathrm{CO}_{2} \mathrm{RR} .{ }^{20,26}$ This result verifies that the Ag dendrite catalyst promotes a fast $\mathrm{CO}_{2} \mathrm{RR}$ rate. The high-current data in Figure 10 reflects the data shown in Figure $\mathrm{S} 7$ and evidences that the $\mathrm{Cu}-\mathrm{Ag}$ foam cathode, in this region, exhibited much higher $\mathrm{CO}$ production current densities than the flat Ag foil. The observable decay in the $\mathrm{CO}$ production was caused by an increase of the hydrogen production and occurred at lower potentials in the case of the Ag foil, preventing a better catalytic performance. 
Figure 10. Applied potential versus $\mathrm{CO}$ production partial current density for Ag dendrites (black squares) and $\mathrm{Ag}$ foil (orange triangles).

In particular, the Tafel evaluation gives insights in the $\mathrm{CO}_{2} \mathrm{RR}$ reaction kinetics. It is well accepted that the first step of the reaction consists in the transfer of one electron to a $\mathrm{CO}_{2}$ molecule to form a $\mathrm{CO}_{2}$ radical absorbed on the catalyst surface. This step is rate determining for the entire reaction process, because it proceeds (as suggested by literature) at much more negative potentials than subsequent steps, in which the $\mathrm{CO}_{2}$ intermediate species reacts with two protons and another electron to form a $\mathrm{CO}$ and a $\mathrm{H}_{2} \mathrm{O}$ molecule. The much lower Tafel slope for the Ag dendrite based cathode, as depicted in Figure 10, therefore suggests that the Ag dendrite surfaces are able to stabilize the $\mathrm{CO}_{2}$ intermediate more efficiently than a flat surface, and thus propel the formation of $\mathrm{CO}$ molecules subsequently. This observation is of highest importance for CO production and was already studied theoretically and experimentally, respectively. ${ }^{36,37}$

Durability is a vital appraisal criterion to estimate a practical electrolysis application. Figure 11 displays the examined long-term stability of the $\mathrm{Ag}$ dendrite coated $\mathrm{Cu}$ foam cathode integrated in our flow cell reactor. For comparison, the potentiostatic measurement of the $\mathrm{Ag}$ foil was also included. At an applied potential of $-0.8 \mathrm{~V}_{\mathrm{RHE}}$ (potential of maximum $F E_{\mathrm{CO}}$ ), the $\mathrm{Cu}-\mathrm{Ag}$ cathode exhibited a current density of around $10 \mathrm{~mA} / \mathrm{cm}^{2}$ which stabilized around this value over the whole reaction session, without the observation of a significant decay (95\% retained after 15 hours of continuous operation). Similarly, the CO faradaic efficiency was also stabilized around $94 \%$ for the whole duration of 15 hours of testing. Measured current density and faradaic efficiency are in accordance to the data presented in Figure S7 and Figure 9b, respectively. Thus, the stability of our prototype reactor was in good agreement with previously reported stabilities for $\mathrm{Ag}$ catalyst based electrodes. ${ }^{21,29}$ The operation robustness of the $\mathrm{Cu}-\mathrm{Ag}$ cathode was additionally confirmed by SEM, TEM, and XRD analysis, respectively (see Figure S9, in the SI). As presented in Figure S9a and S9b, the Ag dendrites preserved their morphology and structural properties, respectively, after long-term electrolysis at $-0.8 \mathrm{~V}_{\text {RHE }}$. The XRD diffraction peaks were identical before and after the 15 hours electrolysis operation (Figure S9c). For the sake of completeness, we also assessed the stability of the Ag foil (Figure 11), which, as expected, also exhibited a very stable operation (tested for 5 hours) with a lower $\mathrm{CO}_{2} \mathrm{RR}$ current density of around $3.4 \mathrm{~mA} / \mathrm{cm}^{2}$ and a $\mathrm{CO}$ selectivity of around $41 \%$, which was in line with the data shown in Figure 9a and 9b, respectively. 


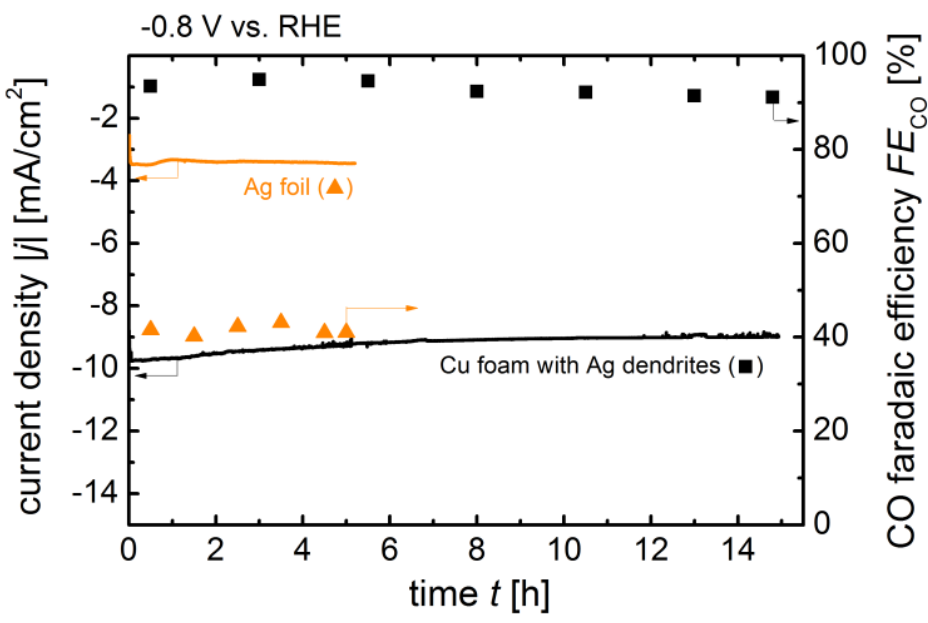

Figure 11. Stability of total $\mathrm{CO}_{2}$ reduction current density (left ordinate) for Ag dendrites (black curve and squares) and $\mathrm{Ag}$ foil (orange curve and triangles) at $-0.8 \mathrm{~V}_{\mathrm{RHE}}$ in $0.5 \mathrm{M} \mathrm{KHCO}_{3}$. The $\mathrm{CO}$ faradaic efficiency of both tested cathodes as a function of operation time is plotted on the right ordinate.

Besides the comparison with flat metallic foil surfaces, the $\mathrm{Cu}$ foam was also checked against a Ni 3D metallic foam, as high surface area catalyst scaffold. Two-dimensional scaffold materials, such as carbon cloth or titanium mesh were not investigated in the present study, mainly because of the lower surface area and lower electrical conductivity compared to $\mathrm{Ni}$ foam. ${ }^{55,56}$ In the $\mathrm{SI}$, the comparison with $\mathrm{Ni}$ foam, regarding Ag catalyst deposition and selectivity towards $\mathrm{CO}$ production is presented. In contrast to the $\mathrm{Cu}$ foam surface, the $\mathrm{Ni}$ foam surface did not give rise to dendritic catalyst growth, but the Ag catalyst was deposited in the form of particles of $1 \mu \mathrm{m}$ in average (see SEM images in the SI, in Figure S10a and Figure S10b). The results on partial $\mathrm{CO}$ and $\mathrm{H}_{2}$ current densities, respectively, presented in Figure S11, furthermore evidence that the $\mathrm{Cu}-\mathrm{Ag}$ cathode showed a significantly higher selectivity towards $\mathrm{CO}$ production than the $\mathrm{Ni}-\mathrm{Ag}$ cathode, which confirms the outstanding performance of the developed $\mathrm{Cu}$-foam based cathode.

\section{Discussion}

The reason for the discrepancy in the activity towards $\mathrm{CO}$ production between the investigated cathodes, observable in Figure $9 \mathrm{~b}$ and Figure S11, respectively, can be explained by several factors. (i) First, the morphology of the deposited Ag catalyst is a crucial parameter regarding $\mathrm{CO}_{2}$ conversion activity. Based on the SEM images it can be deduced that the dendritic structures showing the highest activity towards $\mathrm{CO}$ production (i.e. deposited for $60 \mathrm{~s}$ at $-0.2 \mathrm{~V}_{\mathrm{RHE}}$, Figure 2) possessed more active surface area compared to the other $\mathrm{Ag}$ catalyst morphologies obtained on $\mathrm{Cu}$ foam (e.g. deposition at $-0.05 \mathrm{~V}_{\mathrm{RHE}}$, Figure 2), Cu foil (Figure $\mathrm{S} 4 \mathrm{~b}$ ) and Ni foam (Figure $\mathrm{S} 10 \mathrm{~b}$ ). (ii) Secondly, the better coverage of the $\mathrm{Cu}$ foam with the dendritic catalysts (see deposition at $-0.2 \mathrm{~V}_{\mathrm{RHE}}$ in Figure 2 and Figure 6) ensured that only the Ag catalyst was active in the $\mathrm{CO}_{2} \mathrm{RR}$. As explained earlier, surfaces such as $\mathrm{Cu}$ and $\mathrm{Ni}$ favor other products than $\mathrm{CO} . \mathrm{Cu}$ favors alcohol production and $\mathrm{Ni}$ surfaces are known to favor the hydrogen evolution reaction. The latter is in line with the data on partial current density shown in Figure $\mathrm{S} 11$, which reveals that the Ni-Ag sample showed a higher activity towards $\mathrm{H}_{2}$ production than the $\mathrm{Cu}-\mathrm{Ag}$ sample. (iii) Another important parameter influencing the 
$\mathrm{CO}_{2} \mathrm{RR}$ activity towards $\mathrm{CO}$ is the catalyst surface morphology. As revealed by experiment and simulation (Figure 5), the as-deposited Ag dendrites had a high number of planes. It is well accepted that (110) planes own a high amount of stepped sites, which are highly active sites for $\mathrm{CO}_{2}$-to- $\mathrm{CO}$ conversion. ${ }^{36,37,49}$ To directly measure the ratio of (110) planes vs. more flat sites is however very challenging for $3 \mathrm{D}$ materials in general. To quantify the relative amount of (110) surface, a more convenient approach would be to calculate the ratio of (110) and (111) intensities with the help of XRD measurements. Please note that the diffraction peak of Ag (110) was not observable in the XRD pattern of the $\mathrm{Cu}-\mathrm{Ag}$ foam (Figure 3a) because in face centered cubic structures this reflection is not allowed. Nevertheless, it can be assumed that the (110) structure exists in an amount proportional to that of (220). Consequently, we took the ratio of the $\mathrm{Ag}$ signals (220)/(111) as approximation for the quantity of stepped vs. planar sites, as already described elsewhere. ${ }^{30}$ In Figure 12, the values for the intensity ratios for four investigated samples are plotted as a function of the respective maximum $\mathrm{CO}$ faradaic efficiency. The comparison was conducted for four samples owing different morphologies of the deposited Ag catalysts: Ag dendrites deposited on $\mathrm{Cu}$ foam (for $60 \mathrm{~s}$ at $-0.2 \mathrm{~V}_{\mathrm{RHE}}$ ), which will be called "optimized" hereafter, because the highest $\mathrm{CO}$ productivity was achieved with this sample (morphology: Figure 2 and faradaic efficiency: Figure 8); $\mathrm{Ag}$ catalyst deposited on $\mathrm{Cu}$ foam (for $60 \mathrm{~s}$ at -0.05 $\mathrm{V}_{\mathrm{RHE}}$ ), which will be called "non-optimized", because the corresponding CO productivity of this sample was significantly below the optimized one (morphology: Figure 2 and faradaic efficiency: Figure 8); $\mathrm{Ag}$ catalyst deposited on $\mathrm{Cu}$ foil (morphology: Figure S4b and faradaic efficiency: Figure 9b) and Ag catalyst deposited on Ni foam (morphology: Figure S10b, CO productivity: Figure S11). Ag on $\mathrm{Cu}$ foil and on $\mathrm{Ni}$ foam, respectively, was deposited with the same deposition process as for the optimized sample.

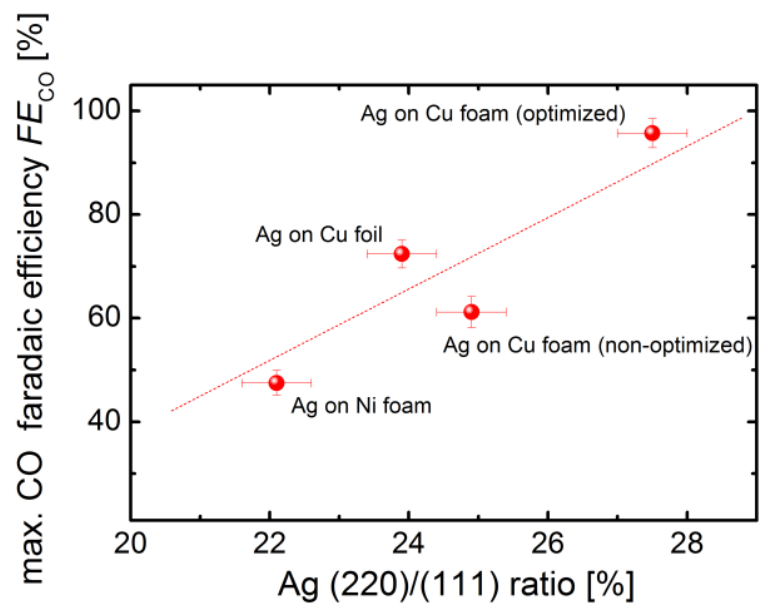

Figure 12. Maximum $C O$ faradaic efficiency $\left(F E_{\mathrm{CO}}\right)$ as a function of the $(220) /(111)$ intensity ratio of the deposited Ag catalyst obtained from the GC and XRD measurements, respectively, for four investigated samples: $\mathrm{Ag}$ deposited on $\mathrm{Cu}$ foam $(60 \mathrm{~s}$ at $-0.2 \mathrm{~V}$, optimized), $\mathrm{Ag}$ deposited on $\mathrm{Cu}$ foam (60 s at $-0.05 \mathrm{~V}$, non-optimized), Ag deposited on Ni foam (60 s at -0.2 $\mathrm{V})$ and $\mathrm{Ag}$ deposited on $\mathrm{Cu}$ foil $(60 \mathrm{~s}$ at $-0.2 \mathrm{~V})$. The error bars indicate standard deviations obtained from 2 experimental repeats (y-axis) and account for inaccuracy in ratio determination from XRD patterns in Figure S12 (x-axis).

From the data in Figure 12, a clear trend of increasing $F E_{\mathrm{CO}}$ with increasing (220)/(111) ratio can be deduced. The XRD measurements from which the $(220) /(111)$ ratios are deduced, can be found in the SI in Figure S12. 
As apparent, the optimized $\mathrm{Ag}$ dendrite catalyst on $\mathrm{Cu}$ foam, exhibiting the highest $F E_{\text {CO }}$ of $95.7 \%$, also showed the highest $(220) /(111)$ intensity ratio of $27.5 \%$. The lowest ratio of $22.1 \%$ was found for the Ag catalyst deposited on $\mathrm{Ni}$ foam, for which also the lowest $F E_{\mathrm{CO}}$ among the investigated samples of $47.5 \%$ was measured. Hence, the experimental findings of this study support the theoretical calculations done by Back et al. showing that Ag surfaces owing a high amount of (220) planes are prone to high $\mathrm{CO}$ productivity. ${ }^{36}$ Overall, the present study successfully generalizes the theoretical findings on $\mathrm{Ag}$ catalyst behavior towards $\mathrm{CO}_{2} \mathrm{RR}$ by employing practical concepts to implement the desired crystallographic orientations of the catalyst surface at large scale.

\section{Conclusions}

In summary, we successfully tailored large-scale metallic foam for highly selective $\mathrm{CO}_{2}$ conversion into $\mathrm{CO}$ at high current and low overpotentials. The experimental observations manifested that the combination of $\mathrm{Ag}$ dendritic catalysts with highly conductive $3 \mathrm{D} \mathrm{Cu}$ foam effectively ameliorated the electrocatalytic performance towards $\mathrm{CO}$ production and gave rise to a stable maximum faradaic efficiency of $95.7 \%$ at $-0.8 \mathrm{~V}_{\mathrm{RHE}}$. A maximum operation current density of $27.3 \mathrm{~mA} / \mathrm{cm}^{2}$ was measured at 1.0 $\mathrm{V}_{\mathrm{RHE}}$. The performance boost, in comparison with other catalyst substrates, was attributed to mainly two features of the $\mathrm{Cu}$ foam based cathode: (i) reduced mass transport limitations due to the amplified 3D electrochemically active contact area between the homogeneously coated $\mathrm{Cu}$ foam and the electrolyte and (ii) the demonstrated high selectivity of the deposited Ag catalyst towards $\mathrm{CO}$ production, which could be attributed to the unique dendrite surface orientations favoring a high density of active sites where $\mathrm{CO}_{2} \mathrm{RR}$ to $\mathrm{CO}$ could take place (high $(220) /(111)$ XRD intensity ratio). Overall, this work exploits a novel pathway for the fabrication and application of robust, efficient, and highly selective metallic foam based electrodes in prototype reactor devices, which are viable for scalable electrochemical reduction of $\mathrm{CO}_{2}$ to $\mathrm{CO}$ at large scale.

\section{Associated Content}

Supporting Information:

Gas product quantification calculation; Electrochemical surface area (ECSA) estimation of $\mathrm{Ag}$ dendrite coated $\mathrm{Cu}$ foam; Comparison between $\mathrm{Cu}$ and $\mathrm{Ni}$ foam for the deposition of Ag catalysts; Additional structural and electrochemical characterization.

\section{Acknowledgments}

Authors acknowledge funding from Generalitat de Catalunya through the CERCA program, 2017 SGR 1246, 2017 SGR 327 and the Spanish MINECO projects MAT2014-59961, ENE2016-80788-C5-5-R and ENE2017-85087, together with the support from REPSOL, S. A.

ICN2 acknowledges support from the Severo Ochoa Programme (MINECO, Grant no. SEV-2013-0295). IREC also acknowledges additional support from the European Regional Development Funds (ERDF, FEDER), (S)TEM part of the present work has been performed in the framework of Universitat Autònoma de Barcelona Materials 
Science $\mathrm{PhD}$ program and the rest in the Nanoscience program of the University of Barcelona.

Authors thank M. López Balastegui, M. Biset-Peiró and S. Murcia-López for their contributions to this work.

F.U. acknowledges financial support from MINECO through Juan de la Cierva fellowship (FJCI-2016-29147).

\section{Author Contributions}

F.U. and T.A. conceived the project and designed the experiments. F.U. carried out the structural and electrochemical experiments under the advisory task of T.A. and J.R.M. F.U. and N.M.C. performed the silver electrodepositions. P.Y.T. and J.A. conducted (S)TEM and EELS analyses. F.U. and J.R.M. interpreted data. F.U. wrote the manuscript. All authors participated in discussions and contributed to editing of the manuscript. J.R.M. supervised the proposed and executed research program.

\section{Competing Financial Interests}

The authors declare no competing financial interests.

\section{References}

[1] Goeppert, A.; Czaun, M.; May, R. B.; Prakash, G. K. S.; Olah, G. A.; Narayanan, S. R. Carbon Dioxide Capture from the Air using a Polyamine based Regenerable Solid Adsorbent

J. Am. Chem. Soc. 2011, 133, 20164.

[2] Schreier, M.; Gao, P.; Mayer, M.T.; Luo, J.; Moehl, T.; Nazeeruddin, M.K.; Tilley, S. D.; Grätzel, M. Efficient and Selective Carbon Dioxide Reduction on Low Cost Protected $\mathrm{Cu}_{2} \mathrm{O}$ Photocathodes using a Molecular Catalyst

Energy Environ. Sci. 2015, 8, 855.

[3] Rosen, J.; Hutchings, G. S.; Lu, Q.; Rivera, S.; Zhou, Y.; Vlachos, D. G.; Jiao, F. Mechanistic Insights into the Electrochemical Reduction of $\mathrm{CO}_{2}$ to $\mathrm{CO}$ on Nanostructured Ag Surfaces

ACS Catal. 2015, 5, 4293.

[4] Asadi, M.; Kim, K.; Liu, C.; Addepalli, A. V.; Abbasi, P.; Yasaei, P.;

Phillips, P.; Behranginia, A.; Cerrato, J. M.; Haasch, R.; Zapol, P.; Kumar, B.;

Klie, R. F.; Abiade, J.; Curtiss, L. A.; Salehi-Khojin, A. Nanostructured

Transition Metal Dichalcogenide Electrocatalysts for $\mathrm{CO}_{2}$ Reduction in Ionic Liquid

Science 2016, 353, 467.

[5] Zhou, X.; Liu, R.; Chen, Y.; Verlage, E.; Francis, S. A.; Lewis, N. S.; Xiang, C. SolarDriven Reduction of $1 \mathrm{~atm}$ of $\mathrm{CO}_{2}$ to Formate at $10 \%$ Energy-Conversion Efficiency by Use of a $\mathrm{TiO}_{2}-$ Protected III-V Tandem Photoanode in Conjunction with a Bipolar Membrane and a $\mathrm{Pd} / \mathrm{C}$ Cathode

ACS Energy Lett. 2016, 1, 764. 
[6] Wang, Y.; Fan, S.; AlOtaibi, B.; Wang, Y.; Li, L.; Mi, Z. A Monolithically Integrated Gallium Nitride Nanowire/Silicon Solar Cell Photocathode for Selective Carbon Dioxide Reduction to Methane

Chem. Eur. J. 2016, 22, 8809.

[7] Kuhl, K. P.; Hatsukade, T.; Cave, E. R.; Abram, D.N.; Kibsgaard, J.; Jaramillo, T.F. Electrocatalytic Conversion of Carbon Dioxide to Methane and Methanol on Transition Metal Surfaces

J. Am. Chem. Soc. 2014, 136, 14107.

[8] Ren, D.; Deng, Y.; Handoko, A. D.; Chen, C. S.; Malkhandi, S.; Yeo, B.S. Selective Electrochemical Reduction of Carbon Dioxide to Ethylene and Ethanol on Copper (I) Oxide Catalysts

ACS Catal. 2015, 5, 2814.

[9] Qiao, J.; Liu, Y.; Hong, F.; Zhang, J. A Review of Catalysts for the Electroreduction of Carbon Dioxide to Produce Low-Carbon Fuels

Chem. Soc. Rev. 2014, 43, 631.

[10] Jin, G.; Werncke, C. G.; Escudié, Y.; Sabo-Etienne, S.; Bontemps, S. Iron-Catalyzed Reduction of $\mathrm{CO}_{2}$ into Methylene: Formation of $\mathrm{C}-\mathrm{N}, \mathrm{C}-\mathrm{O}$, and $\mathrm{C}-\mathrm{C}$ Bonds

J. Am. Chem. Soc. 2015, 137, 9563.

[11] Wender, I. Reactions of Synthesis Gas

Fuel Process. Technol. 1996, 48, 189.

[12] Schreier, M.; Curvat, L.; Giordano, F.; Steier, L.; Abate, A.; Zakeeruddin, S. M.; Luo, J.; Mayer, M. T.; Grätzel, M. Efficient Photosynthesis of Carbon Monoxide from $\mathrm{CO}_{2}$ using Perovskite Photovoltaics

Nat. Commun. 2015, 6, 7326.

[13] Jang, Y. J.; Jeong, I.; Lee, J.; Lee, J.; Ko, M.J.; Lee, J.S. Unbiased Sunlight-Driven Artificial Photosynthesis of Carbon Monoxide from $\mathrm{CO}_{2}$ Using a ZnTe-Based Photocathode and a Perovskite Solar Cell in Tandem ACS Nano 2016, 10, 6980.

[14] Chen, Y.; Li, C. W.; Kanan, M. W. Aqueous $\mathrm{CO}_{2}$ Reduction at Very Low Overpotential on Oxide-Derived Au Nanoparticles

J. Am. Chem. Soc. 2012, 134, 19969.

[15] Ramdin, M.; de Loos, T. W.; Vlugt, T. J. H. State-of-the-Art of

$\mathrm{CO}_{2}$ Capture with Ionic Liquids

Ind. Eng. Chem. Res. 2012, 51, 8149.

[16] Rosen, B.A.; Salehi-Khojin, A.; Thorson, M. R.; Zhu, W.; Whipple, D. T.; Kenis, P. J. A.; Masel, R.I. Ionic Liquid-Mediated Selective Conversion of $\mathrm{CO}_{2}$ to $\mathrm{CO}$ at Low Overpotentials

Science 2011, 334, 643.

[17] DiMeglio, J.L.; Rosenthal, J. Selective Conversion of $\mathrm{CO}_{2}$ to $\mathrm{CO}$ with High Efficiency Using an Inexpensive Bismuth-Based Electrocatalyst J. Am. Chem. Soc. 2013, 135, 8798.

[18] Li, C.W.; Kanan, M.W. $\mathrm{CO}_{2}$ Reduction at Low Overpotential on $\mathrm{Cu}$ Electrodes Resulting from the Reduction of Thick $\mathrm{Cu}_{2} \mathrm{O}$ Films J. Am. Chem. Soc. 2012, 134, 7231. 
[19] Kostecki, R.; Augustynski, J. Photon-Driven Reduction Reactions on Silver

J. Appl. Electrochem. 1993, 23, 567.

[20] Liu, S.; Tao, H.; Zeng, L.; Liu, Q.; Xu, Z.; Liu, Q.; Luo, J.-L. ShapeDependent Electrocatalytic Reduction of $\mathrm{CO}_{2}$ to $\mathrm{CO}$ on Triangular Silver Nanoplates

J. Am. Chem. Soc. 2017, 139, 2160.

[21] Zhang, L.; Wang, Z.; Mehio, N.; Jin, X.; Dai, S. Thickness-and ParticleSize-Dependent Electrochemical Reduction of Carbon Dioxide on Thin-Layer Porous Silver Electrodes ChemSusChem 2016, 9, 428.

[22] Ma, M.; Trzesniewski, B.J.; Xie, J.; Smith, W.A. Selective and Efficient Reduction of Carbon Dioxide to Carbon Monoxide on Oxide-Derived Nanostructured Silver Electrocatalysts

Angew. Chem. Int. Ed. 2016, 55, 1.

[23] Kim, C.; Jeon, H.S.; Eom, T.; Jee, M.S.; Kim, H.; Friend, C.M.; Koun Min, B.; Hwang, Y.J. Achieving Selective and Efficient Electrocatalytic Activity for $\mathrm{CO}_{2}$ Reduction Using Immobilized Silver Nanoparticles J. Am. Chem. Soc. 2015, 137, 13844.

[24] Lu, Q.; Rosen, J.; Zhou, Y.; Hutchings, G.S.; Kimmel, Y.C.; Chen, J.G.; Jiao, F. A Selective and Efficient Electrocatalyst for Carbon Dioxide Reduction

Nat. Comm. 2014, 5, 3242.

[25] Zhang, Y.; Ji, L.; Qiu, W.; Shi, X.; Asiri, A. M.; Sun, X. Iodide-Derived Nanostructured Silver Promotes Selective and Efficient Carbon Dioxide Conversion into Carbon Monoxide Chem. Commun. 2018, 54, 2666.

[26] Cho, M.; Seo, J.-W.; Song, J. T.; Lee, J.-Y.; Oh, J. Silver

Nanowire/Carbon Sheet Composites for Electrochemical Syngas Generation with Tunable $\mathrm{H}_{2} / \mathrm{CO}$ Ratios ACS Omega 2017, 2, 3441.

[27] Qiu, W.; Liang, R.; Luo, Y.; Ciu, G.; Qiu, J.; Sun, X. A Br ${ }^{-}$Anion Adsorbed Porous Ag Nanowire Film: in situ Electrochemical Preparation and Application Toward Efficient $\mathrm{CO}_{2}$ Electroreduction to $\mathrm{CO}$ with High Selectivity

Inorg. Chem. Front. 2018, 5, 2238.

[28] Back, S.; Yeom, M. S.; Jung, Y. Active Sites of Au and Ag Nanoparticle Catalysts for $\mathrm{CO}_{2}$ Electroreduction to $\mathrm{CO}$

ACS Catal. 2015, 5, 5089.

[29] Daiyan, R.; Lu, X.; Ng, Y. H.; Amal, R. Highly Selective Conversion of $\mathrm{CO}_{2}$ to $\mathrm{CO}$ Achieved by a Three-Dimensional Porous Silver Electrocatalyst ChemistrySelect 2017, 2, 879.

[30] Ham, Y.S.; Choe, S.; Kim, M. J.; Lim, T.; Kim, S.-K.; Kim, J.

Electrodeposited Ag Catalysts for the Electrochemical Reduction of $\mathrm{CO}_{2}$ to $\mathrm{CO}$ J. Appl. Catal. B: Environ. 2017, 208, 35.

[31] Fan, M.; Garbarino, S.; Botton, G. A.; Tavares, A.C.; Guay, D. Selective Electroreduction of $\mathrm{CO}_{2}$ to Formate on 3D [100] Pb Dendrites with Nanometer-sized Needle-like Tips J. Mater. Chem. A 2017, 5, 20747. 
[32] Won, D.H.; Choi, C.H.; Chung, J.; Chung, M.W.; Kim, E.-H.; Woo, S.I. Rational Design of a Hierarchical Tin Dendrite Electrode for Efficient Electrochemical Reduction of $\mathrm{CO}_{2}$

ChemSusChem 2015, 8, 3092.

[33] Medina-Ramos, J.; Pupillo, R. C.; Keane, T. P.; DiMeglio, J. L.; Rosenthal, J. Efficient Conversion of $\mathrm{CO}_{2}$ to $\mathrm{CO}$ Using Tin and Other Inexpensive and Easily Prepared Post-Transition Metal Catalysts J. Am. Chem. Soc. 2015, 137, 5021.

[34] Natter, H.; Hempelmann, R. Tailor-made Nanomaterials Designed by Electrochemical Methods

Electrochem. Acta 2003, 49, 51.

[35] Gurrappa, I.; Binder, L. Electrodeposition of Nanostructured Coatings and their Characterization - A Review

Sci. Technol. Adv. Mater. 2008, 9, 043001.

[36] Back, S.; Yeom, M. S.; Jung, Y. Active Sites of Au and Ag Nanoparticle Catalysts for $\mathrm{CO}_{2}$ Electroreduction to $\mathrm{CO}$

ACS Catal. 2015, 5, 5089.

[37] Hoshi, N.; Kato, M.; Hori, Y. Electrochemical Reduction of $\mathrm{CO}_{2}$ on

Single Crystal Electrodes of Silver Ag (111), Ag (100) and Ag (110)

J. Electroanal. Chem. 1997, 400, 283.

[38] Salomé, S.; Rego, R.; Oliveira, M.C. Development of Silver-gas Diffusion Electrodes for the Oxygen Reduction Reaction by Electrodeposition

Mater. Chem. Phys. 2013, 143, 109.

[39] Urbain, F.; Tang, P.; Carretero, N. M.; Andreu, T.; Gerling, L. G.; Voz, C.; Arbiol, J.; Morante, J.R. A Prototype Reactor for Highly Selective Solardriven $\mathrm{CO}_{2}$ Reduction to Synthesis Gas using Nanosized Earth-Abundant Catalysts and Silicon Photovoltaics

[40] Irtem, E.; Andreu, T.; Parra, A.; Hernández-Alonso, M. D.; García-

Rodríguez, S.; Riesco-García, J. M.; Penelas-Pérez, G.; Morante, J.R. Lowenergy Formate Production from $\mathrm{CO}_{2}$ Electroreduction using Electrodeposited Tin on GDE

J. Mater. Chem. A 2016, 4, 13582.

Energy Environ. Sci. 2017, 10, 2256.

[41] Hernández-Alonso, M. D.; Penelas-Pérez, G.; Andreu, T.; Irtem, E.; Parra, A.; Fábrega, C.; Morante, J.R. Filter-press Photoelectrochemical Water Oxidation and $\mathrm{CO}_{2}$ Reduction Cell, Patent WO/2016/097247, 23 June 2016.

[42] Min, S.; Yang, X.; Lu, A.-Y.; Tseng, C.-C.; Hedhili, M. N.; Li, L.-J.;

Huang, K.-W. Low Overpotential and High Current $\mathrm{CO}_{2}$ Reduction with

Surface Reconstructed Cu Foam Electrodes

Nano Energy 2016, 27, 121.

[43] Yu, J.; Xiong, J.; Cheng, B.; Liu, S. Fabrication and Characterization of $\mathrm{Ag}-\mathrm{TiO}_{2}$ Multiphase Nanocomposite Thin Films with Enhanced Photocatalytic Activity

Appl. Catal. B: Environ. 2005, 60, 211. 
[44] Stathatos, E.; Lianos, P.; Falaras, P.; Siokou, A. Photocatalytically Deposited Silver Nanoparticles on Mesoporous $\mathrm{TiO}_{2}$ Films

Langmuir 2000, 16, 2398.

[45] Arbiol, J.; Fontcuberta i Morral, A.; Estradé, S.; Peiró, F.; Kalache, B.; Roca i Cabarrocas, P.; Morante, J.R. Influence of the (111) Twinning on the Formation of Diamond Cubic/Diamond Hexagonal Heterostructures in $\mathrm{Cu}$ Catalyzed Si Nanowires

J. Appl. Phys. 2008, 104, 064312.

[46] Spirkoska, D.; Arbiol, J.; Gustafsson, A.; Conesa-Boj, S.; Glas, F.; Zardo, I.; Heigoldt, M.; Gass, M. H.; Bleloch, A. L.; Estrade, S.; Kaniber, M.; Rossler, J.; Peiro, F.; Morante, J.R.; Abstreiter, G.; Samuelson, L.; Fontcuberta i Morral, A. Structural and Optical Properties of High Quality Zincblende/Wurtzite GaAs Nanowire Heterostructures

Physical Review B 2009, 80, 245325.

[47] Utama, M. I. B.; de la Mata, M.; Magen, C.; Arbiol, J.; Xiong, Q. Twinning-, Polytypism-, and Polarity-Induced Morphological Modulation in Nonplanar Nanostructures with van der Waals Epitaxy

Adv. Func. Mater. 2013, 23, 1636.

[48] Ulissi, Z. W.; Tang, M. T.; Xiao, J.; Liu, X.; Torelli, D. A.; Karamad, M.; Cummins, K.; Hahn, C.; Lewis, N. S.; Jaramillo, T. F.; Chan, K.; Nørskov, J.K. Machine-Learning Methods Enable Exhaustive Searches for Active Bimetallic Facets and Reveal Active Site Motifs for $\mathrm{CO}_{2}$ Reduction

ACS Catal. 2017, 7, 6600.

[49] Nesbitt, N-T.; Ma, M.; Trześniewski, B.J.; Jaszewski, S.; Tafti, F.F.; Burns, M.J.; Smith, W.A.; Naughton, M.J. Au Dendrite Electrocatalysts for $\mathrm{CO}_{2}$ Electrolysis

J. Phys. Chem. C, 2018, 122, 10006.

[50] Whipple, D. T.; Finke, E. C.; Kenis, P.J.A. Microfluidic Reactor for the Electrochemical Reduction of Carbon Dioxide: the Effect of $\mathrm{pH}$

Electrochem. Solid State Lett. 2010, 13, D109.

[51] Delacourt, C.; Ridgway, P. L.; Kerr, J. B.; Newman, J. Design of an Electrochemical Cell Making Syngas $\left(\mathrm{CO}+\mathrm{H}_{2}\right)$ from $\mathrm{CO}_{2}$ and $\mathrm{H}_{2} \mathrm{O}$ Reduction at Room Temperature

J. Electrochem. Soc. 2008, 155, B42.

[52] Salehi-Khojin, A.; Molly Jhong, H.-R.; Rosen, B. A.; Zhu, W.; Ma, S.; Kenis, P. J. A.; Masel, R.I. Nanoparticle Silver Catalysts that Show Enhanced Activity for Carbon Dioxide Electrolysis

J. Phys. Chem. C 2013, 117, 1627.

[53] Verma, S.; Lu, X.; Ma, S.; Maseld, R. I.; Kenis, P.J.A. The Effect of Electrolyte Composition on the Electroreduction of $\mathrm{CO}_{2}$ to $\mathrm{CO}$ on $\mathrm{AgBased}$ Gas Diffusion Electrodes

Phys. Chem. Chem. Phys. 2016, 18, 7075-7084.

[54] Hernández, S.; Farkhondehfal, M.A.; Sastre, F.; Makkee, M.; Saraccob, G.; Russo, N. Syngas Production from Electrochemical Reduction of $\mathrm{CO}_{2}$ : Current Status and Prospective Implementation Green Chem., 2017, 19, 2326-2346. 
[55] Wang, Y.; Yuan, A.; Wang, X. Pseudocapacitive Behaviors of Nanostructured Manganese Dioxide/Carbon Nanotubes Composite Electrodes in Mild Aqueous Electrolytes: Effects of Electrolytes and Current Collectors

J Solid State Electrochem., 2008, 12, 1101-1107.

[56] Euret, C.; Oliveira Vilar, E.; Bezerra Cavalcanti, E. Carbon Fibre Cloth as an Electrode Material: Electrical Conductivity and Mass Transfer

J. Appl. Electrochem., 2002, 32, 1175-1182. 

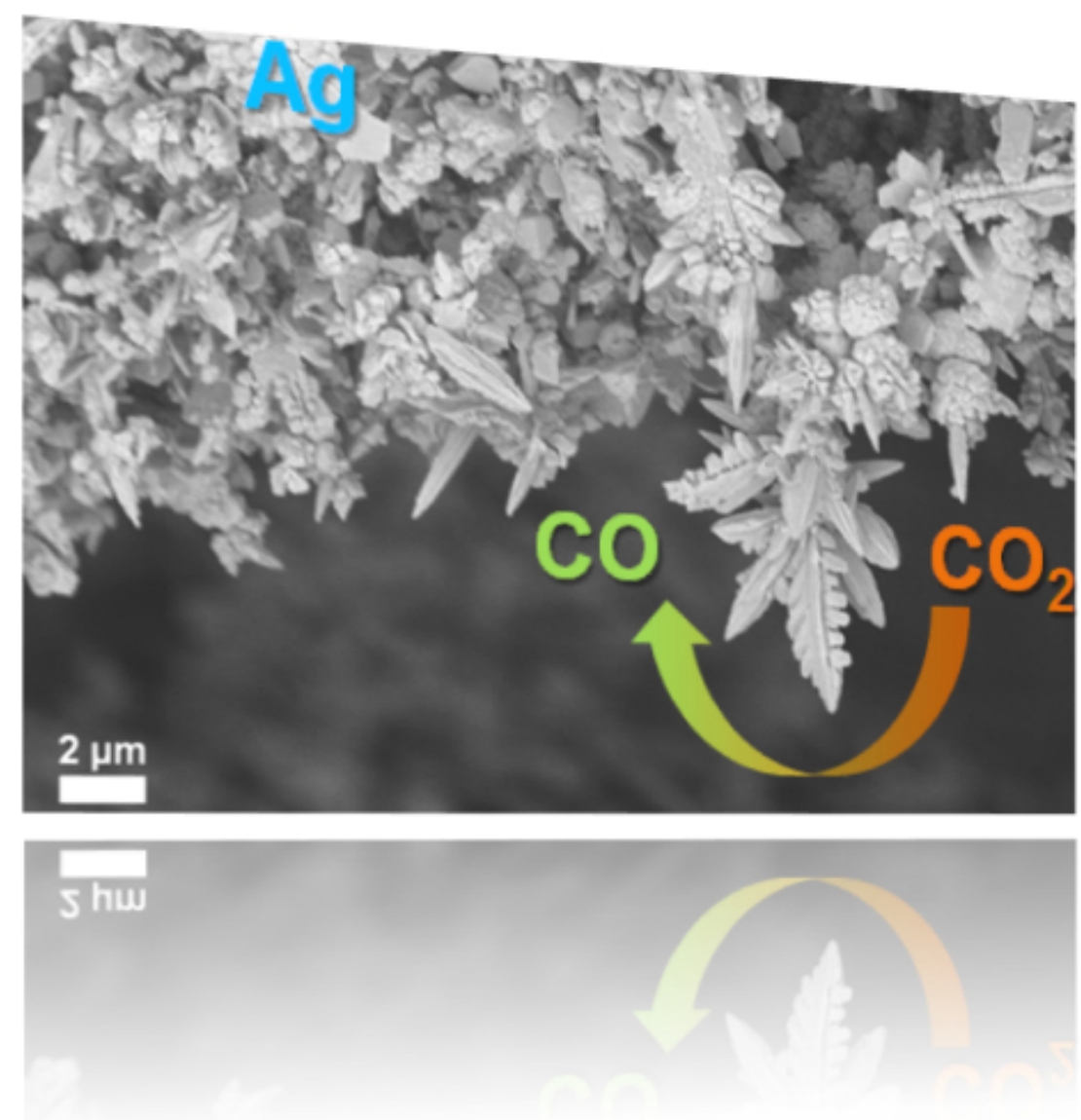